\title{
Equivalent inter- and intramodality long-term priming: Evidence for a common lexicon for words seen and words heard
}

\author{
G. Lukatela, Thomas Eaton, Miguel A. Moreno, and M. T. Turvey \\ University of Connecticut, Storrs, Connecticut \\ and Haskins Laboratories, New Haven, Connecticut
}

\begin{abstract}
Weaker inter- than intramodality long-term priming of words has promoted two hypotheses: (1) separate visual and auditory lexicons and (2) modality dependence of implicit memory. In five experiments, we employed manipulations aimed to minimize study-test asymmetries between the two priming conditions. Activities at visual and auditory study were matched, words were phonologically consistent, and study modality was manipulated between subjects. Equal magnitudes of inter- and intramodality priming were found in experiments with visual and auditory stem completion at test, with visual fragment completion at test, and with visual and auditory perceptual identification at test. A within-subjects experiment yielded the conventional intramodality advantage. The results point to a single amodal lexicon and to modality-independent phonological processing as the basis of implicit word memory.
\end{abstract}

A frequent experimental observation within implicit memory paradigms is that word priming is superior when the prime is presented in the same modality as the test word (visual-study-visual-test [VV] and auditory-studyauditory-test $[\mathrm{AA}]$ ), as compared with when the prime is presented in a different modality (auditory-study-visualtest $[\mathrm{AV}]$ and visual-study-auditory-test [VA]). This frequent observation has motivated two important theoretical conclusions.

One conclusion is in respect to the issue of whether the same lexicon underlies visual and auditory word recognition. In Morton's (1969) original logogen model, a word's representation in long-term memory (its logogen) is strengthened by both visual and auditory experiences with the word. A logogen's strength is measured by the ease, or speed, with which the logogen reaches a criterion level of activation. Morton's original proposal could not be preserved, however, in the face of experiments demonstrating substantial intramodal priming but negligible intermodal priming (e.g., Morton, 1979). A key feature of the original logogen theory was that once a logogen is made to fire, either by sight or by sound, it returns only slowly to its original state. Consequently, if the two modalities share the same logogen system, an earlier auditory experience of a word must help a later visual experience of that same word, and vice versa. Furthermore, an earlier experience in a modality different from the later experience should be as beneficial as an earlier experience in the same modality. Without convincing evidence in favor of the latter expectations, Morton $(1979,1980,1982)$ was forced to distinguish two memory systems, one for words as read and one for words as heard. Any communication between the two stores could occur only through what he called the cognitive system - the site of meanings, cognitive strategies, and decision making. Most subsequent discussions of the relation between perceiving words by ear and by eye have sided with Morton's final assessment of independent lexicons (e.g., Coltheart, Rastle, Perry, Langdon, \& Ziegler, 2001; Ellis \& Young, 1996; Patterson \& Sewell, 1987). Indeed, Morton's conclusion was a primary motivation for the development of dual-route theory (see the historical survey in Coltheart et al., 2001).

The other conclusion, motivated by superior priming in within-modality than in cross-modality conditions, is in respect to the issue of what underlies the distinction between implicit and explicit memory measures. One interpretation is that the two measures index two separate memory systems (e.g., Tulving \& Schacter, 1990). Another is that they reflect a difference between the kinds of processes and conditions shared between the original experiencing of an event (call it study) and the subsequent testing of the memory for that event (e.g., Blaxton, 1989; Roediger \& Blaxton, 1987). The latter interpretation is continuous with the ideas of transfer-appropriate processing (TAP; Morris, Bransford, \& Franks, 1977) and encoding specificity (ES; Tulving \& Thomson, 1973), ideas that are at the core of the contemporary account of forgetting (Neath \& Surprenant, 2003). The central thesis is that whether a given condition of study leads to good or poor memory performance depends on the type of test.

G. Lukatela, georgije.lukatela@haskins.yale.edu 
The extreme comparison of study-test pairings is that between (1) incidental study followed by an indirect test and (2) intentional study followed by a direct test. Study is incidental in an experiment when conditions (typically instructions) orient attention to an information-processing goal different from that of remembering the presented materials. A memory test is indirect in an experiment when conditions orient attention to a current activity involving (surreptitiously) the material at study, without drawing attention to the prior incidence of study. Study-Test Pairing (1) would be considered ideal for investigating implicit memory. Study-Test Pairing (2) would be considered ideal for investigating explicit memory.

The methodological distinction between implicit and explicit memory is often correlated, however, with a processing difference. Pairing (1) is said to bias processing at study and test to the physical, perceptually detectable details. Pairing (2) is said to encourage, in addition, a conceptual level of processing at study and test. In the terms introduced by Jacoby (1983), memory performance in Pairing (1) is strictly data driven, and memory performance in Pairing (2) is predominantly conceptually driven.

The significance of the contrast between inter- and intramodality priming for the issue of what is the basis on which performance is distinguished in implicit memory conditions and explicit memory conditions can now be identified. In Pairing (1), visual study and auditory test or auditory study and visual test differ in their data-driven processes, as compared with study and test in the same modality (VV or AA). Consequently, the evidence provided by superior intramodality priming is taken to be twofold. First, it is taken to be evidence that implicit memory conditions are those that involve a particular kind of processing. Second, it is taken to be evidence that implicit memory performance depends on the degree to which the specifics of that particular kind of processing in the study phase are duplicated in the test phase. As a number of investigators have remarked, cross-modal priming is likely to be inferior because there is less transfer of data-driven processing from study to test (e.g., Bassili, Smith, \& MacLeod, 1989; Habib \& Nyberg, 1997; Roediger \& McDermott, 1993). What the test does not duplicate, presumably, are the sensory modality details present at study.

Our primary concern in the present article is the hypothesis of a common lexicon for visual and auditory word recognition. As will become apparent, addressing this primary concern is intertwined with the TAP account of implicit memory.

Morton was led to reject the common lexicon hypothesis on the basis of experiments involving long-term priming conditions typical of implicit memory studies. Winnick and Daniel (1970) and Clarke and Morton (1983) used visual perceptual identification, at or near threshold, of words that had been presented earlier for incidental study either visually or aurally. The present experiments expanded and elaborated upon this research strategy. First, the present experiments employed stem completion (ele for elephant), word fragment completion ( $e_{-} e_{-}$an_for elephant), and the perceptual identification of words embedded in noise, as the indirect tests. Second, the present experiments were so designed as to render all four conditions - the two within-modality conditions and the two between-modality conditions - as symmetrical as was methodologically feasible. The motivation for doing so derived, in part, from concerns expressed in the literature that differences between inter- and intramodal performance may have less to do with modal contrasts than with subtle unplanned and unobtrusive differences among conditions (e.g., Brown, Neblett, Jones, \& Mitchell, 1991; Scarborough, Cortese, \& Scarborough, 1977; see Poulton, 1982). Further motivation for symmetry among the four conditions was the need to isolate the effects of processing at the lexical level. Experiments by Weldon (1991) have shown that, for word stimuli, data-driven processing comprises sensory processing and lexical processing, with the latter critical for the priming of performance on indirect tests. The experiments suggested that priming is induced by lexical processing and then amplified by the match between sensory stimulation at study and test (Roediger, Srinivas, \& Weldon, 1989). Accordingly, to the extent that sensory processing is asymmetric across the four conditions, a potential lexical commonality between word identification by ear and by eye may be obscured. In more emphatic terms, some of the processing transferred from study to test may be inappropriate.

The lexical processing said to be key to priming in implicit memory tasks is in need of clarification. Performance on indirect tests, such as stem completion and fragment completion, is affected weakly (e.g., Graf \& Mandler, 1984; Graf, Mandler, \& Haden, 1982; Roediger, Weldon, Stadler, \& Riegler, 1992) but systematically (Brown \& Mitchell, 1994; Challis \& Brodbeck, 1992) by depth of processing. Shallow and deep processing of the words at study yield similar effects at test. The implication is that stem and fragment completion are constrained by an aspect of lexical processing common to both more shallow and less shallow forms of study. That aspect is most likely word phonology. When a word is primed by a picture, the level of processing matters. It does so, however, opposite to expectation and in conformity with the theory of TAP: Simple naming of the picture at study leads to better stem completion than does semantic evaluation of the picture at study (Roediger et al., 1992). More to the point, performance on auditory stem completion improves systematically with increased opportunity at visual study to encode the words phonologically and phonetically (reading with articulatory suppression, reading quietly, or reading aloud; McClelland \& Pring, 1991).

The present research consisted of five experiments. They implemented a number of steps identified as important to achieving the desired symmetry highlighted above. Below, we will identify these steps in terms of the stem completion task investigated in Experiments 1 and 2.

In the first step, identified as identical study, we sought to ensure that the orientation at study would be the same whether the words were experienced visually or aurally. For example, in Experiment 1, the participants were invited by instruction and conditions to adopt a passive attitude at study. No specific incidental task was required of them. 
The purpose of this step was to avoid, as far as possible, modality-specific biases in study-to-test transfer. A shallow auditory task ostensibly similar to a corresponding shallow visual task is still likely to differ in its appropriateness to the processing requirements of a subsequent visual test.

In a second step, we sought to achieve equal encoding and equal retrieving. It entailed removing potential word-specific differences between auditory study and visual study and between auditory test and visual test. This second measure was in keeping with the observation of Brooks and colleagues (Brooks, Gibson, Friedman, \& Yesavage, 1999) that word-specific factors may be more potent determinants of long-term priming than are conventional manipulations (e.g., modality and processing task at study). Of particular concern for stem (and fragment) completion tasks is the phonological consistency of the words selected for the experiment. Using words with written forms that were unambiguous in respect to pronunciation enhanced the likelihood that visual presentation would activate the same phonological representations in lexical memory and, consequently, the same phonetic representations, as would auditory presentation. An additional particular concern was the phonetic reliability of the stem in the auditory stem completion test. To increase reliability, most of the study words were stressed on the first syllable, and first syllables were used as stems. Furthermore, all aurally presented words were spoken with the regional accent common to the majority of the participants. The application of the two constraints, that on the orthography and that on the phonetics, was essentially the constraint of spelling-sound consistency in both directions.

A third step was directed at rendering the three phases composing the standard trial of an implicit memory experiment — study, interpolated activity, and test—as selfcontained and independent. Each phase had its own task and task evaluation, suggesting closure, and each task and evaluation was so distinguished procedurally as to suggest independence. A fourth step, identified as modal homogeneity, entailed minimizing switches in emphasis between looking and listening during study. In conditions of visual study in Experiments 1 and 2, a participant read the instructions and viewed the visually presented words silently. In conditions of auditory study, a participant listened to the instructions and listened to the aurally presented words in silence. The idea was to deemphasize modality.

Practical implementation of Steps 2 and 4 called for the final step: a between-subjects design. Variables shown to have an effect on memory when manipulated in a mixedlist manner may fail to have an effect or prove to have a different effect when manipulated in a pure-list manner (e.g., Brown et al., 1991; Hopkins \& Edwards, 1972; Nilsson, Wright, \& Murdock, 1975; Slamecka \& Katsaiti, 1987; Underwood, 1983). Poulton (1982) has commented that despite its obvious statistical advantages, the within-subjects design is prone to asymmetric transfer of strategies among the experimental conditions. A strategy employed in one condition may be used inappropriately in another condition. Transferred but inappropriate strategies (which frequently are not obvious) will bias the results in unknown ways. For example, Slamecka and Kat- saiti (1987) attributed the generation effect to participants' spending more time in the within-subjects design rehearsing the generated items than rehearsing the read items (but see Begg, Snider, Foley, \& Goddard, 1989; Burns, 1992).

\section{EXPERIMENT 1}

Experiment 1 implemented the steps identified above as a strong test of the hypothesis of separate visual and auditory lexicons. The experiment focused on the contrast between auditory-to-visual transfer and visual-to-visual transfer. On finding a reliable instance of auditory-to-visual priming but superior visual-to-visual priming, Clarke and Morton (1983) remarked: "We still have cause to separate the visual and auditory input systems, however, since the difference between auditory and visual priming remains" (p. 93). From the introductory remarks, it can be presumed that weaker auditory-to-visual transfer, at least in part and in some experiments, is due to factors extraneous to the activation of a modality-independent lexical representation.

\section{Method}

Participants. Forty undergraduates at the University of Connecticut participated in the experiment in partial fulfillment of an introductory psychology course requirement. Each participant was assigned randomly to one of four groups, with 10 participants in each group. All participants in Experiment 1 (and Experiments 2-5) gave their consent in accordance with the University of Connecticut's internal review board's regulations for studies with human participants.

Materials. Each word was 5-10 letters and 1-4 syllables in length. The average Celex frequency (Dutch Center for Lexical Information, 1995) was $14.51,8.49$, and 11.42 for critical words, test fillers, and study fillers, respectively. No stems were repeated. More specifically, there was no repetition across words of letter sequences for the initial 3 or 4 letters in visual word stems. Hence, in visual stem completion, each stem could be completed unequivocally by only one critical target word. At the same time, each stem could be completed by three or more words not used at study. A male speaker (T.E.) of American English native to New England was recorded producing the auditory study words. The same speaker was used for all the spoken word stimuli in the present series of experiments. The recordings were digitized with 16 bits per sample, using the SoundEdit 16 software.

A basic set of 86 concrete words was selected in a nonprimed stem completion experiment. The completion rate for the selected words ranged from 5\% to $35 \%$. The critical words were the first 24 identified in Appendix A. Twenty-six words were designated as study fillers, and the remaining 36 words were assigned the role of test fillers.

Design. The methodological steps identified in the introduction were applied to the two conditions targeted for examination in Experiment 1.

The base set of 24 critical stimuli was divided by random assignment into two halves-the $a$-subset and the $b$-subset. Two experimental lists of 38 words were prepared for study that differed only in the subset of critical stimuli: List A included only the $a$-subset, and List B included only the $b$-subset. The combination of experimental lists and study modalities defined four groups of participants: visual-study-A-visual-test, visual-study-B-visual-test, auditorystudy-A-visual-test, and auditory-study-B-visual-test. At test, all four groups saw the same 60 printed word stems that included the 24 critical word stems and 36 filler stems unrelated to the filler words at study. For each group at test, therefore, 12 critical stems had been primed by study, and 12 had not. Studied words were limited to $20 \%$ of the test words in order to discourage the adoption of an explicit 
study-based retrieval strategy at test (Butler \& Berry, 2001; Roediger $\&$ Geraci, 2005). To further discourage such a strategy, the sequence of 60 word stems was presented in a specific and unchanging order. Appendix B provides a typical test sequence. The initial 10 stems were fillers. The remaining 26 filler stems, plus the 12 unprimed critical word stems, were presented in alternation with the 12 studied word stems, ensuring nonadjacency of the studied word stems.

For each participant in each group, stem completion of the 12 primed critical stems (designated "P" in Appendix B) yielded the participant's transfer measure, and stem completion of the 12 unprimed critical stems (designated " $\mathrm{C}$ " in Appendix B) yielded the participant's baseline measure of stem completion performance.

The above manipulations led to a $2 \times 2 \times 2$ design, where two priming conditions (primed or nonprimed) were crossed with two modalities of study (visual or auditory) and two subgroups. The priming condition was a within-subjects factor, whereas group and modality were between-subjects factors.

Procedure. The participants were assigned randomly to each condition as they reported to the laboratory. They were tested individually, with each participant seated comfortably in an armchair in front of a screen monitor that was flanked by two loudspeakers. The participants were informed, either in writing or orally (depending on condition), that the experiment involved a sequence of three different tasks. Potential relations among the tasks were not mentioned.

The study phase occurred in two versions. In the visual version, the participant was requested by written instructions to read silently each word as it appeared on the monitor screen. In the auditory version, the participant was requested by spoken instructions to listen with eyes closed to words played over loudspeakers. In the visual version of the study phase, a study item was presented on the screen for $6 \mathrm{sec}$, followed by a 6-sec blank screen. In the auditory version of study, each spoken word was played at a comfortable conversational level from a loudspeaker. Each auditory item was played twice in succession, with $2 \mathrm{sec}$ between each playing. In both versions of the study phase, the interitem presentation interval was $12 \mathrm{sec}$, and in both versions, words were randomized differently from participant to participant. At the conclusion of the study phase of both versions, the participant was asked orally to elaborate the meaning of one word from the study list (a semantically ambiguous word drawn from the set of study fillers by the experimenter).

The study phase was followed by an interpolated task described verbally to the participant as a long-term memory test. The task was to write down as many U.S. presidents as they could remember during a 5-min period (Roediger et al., 1992).

Following the interpolated task, the participants performed visual stem completion. Instructions were given in writing to complete each stem, printed on a test sheet, with the first word that came to mind and to resist returning to stems that had been completed. The written instructions also informed the participant of unacceptable completions - by nominal inflection, verbal inflection, or any type of derivation (examples were provided). Performance of the stem completion test was self-paced.

\section{Results and Discussion}

A completion was scored as correct only if it exactly matched the target word. For VV, the proportion of primed completions was .45 , and the proportion of nonprimed completions was .18. For AV, the proportion of primed completions was .44 , and the proportion of nonprimed completion was .10. The results, depicted in Figure 1, suggest an equivalence of $\mathrm{VV}$ and $\mathrm{AV}$. A $2 \times 2 \times 2$ ANOVA conducted on subject means $\left(F_{1}\right)$ and item means $\left(F_{2}\right)$ confirmed the suggestion.

Group and study modality were between-subjects factors, whereas priming was a within-subjects factor. The ANOVA revealed only a reliable effect of priming $\left[F_{1}(1,36)=170.13, p<.0001, P_{1}(\right.$ power $)=1.0$;
$F_{2}(1,22)=87.57, p<.0001, P_{2}($ power $\left.)=1.0\right]$. Neither study modality $\left[F_{1}(1,36)<1, P_{1}\right.$ (power) $=.07$; $F_{2}(1,22)=3.78, p>.05, P_{2}($ power $\left.)=.45\right]$ nor the study modality $\times$ priming interaction $\left[F_{1}(1,36)<1\right.$, $P_{1}($ power $)=.07 ; F_{2}(1,22)=2.30, p>.05, P_{2}($ power $)=$ .29] was significant. A planned comparison confirmed that AV did not differ from VV $(F \mathrm{~s}<1)$. In sum, contrary to the standard observation, Experiment 1 showed an equivalence of inter- and intramodal priming.

\section{EXPERIMENT 2}

The second experiment introduced the complete modality design (visual and auditory study combined with visual and auditory tests) within a modification of Experiment 1 . The modification was in respect to the instruction in Experiment 1 to perceive the study words passively. In Experiment 2, the participants were given a definite task at visual and auditory study. They were instructed to image the words. This task's purpose was twofold: to foster uniformity among the participants in study activity (the passive instruction would have allowed diversity) and to check on contamination. Imagery at study, as a higher level of word processing than silent naming or quiet listening, tends to help direct, but not indirect, tests (e.g., Roediger \& Blaxton, 1987). If the level of visual stem completion in Experiment 2 were raised relative to that in Experiment 1, it would be important to consider the possibility that explicit recall had contaminated performance in Experiment 1.

\section{Method}

Participants. Eighty-eight undergraduates at the University of Connecticut participated in the experiment in partial fulfillment of an introductory psychology course requirement. Each participant was assigned randomly to one of eight groups, with 11 participants in each group.

Materials and Design. Materials were the same as those in Experiment 1, except for two modifications: (1) The set of critical words was expanded to 30 (see Appendix A), and (2) an auditory

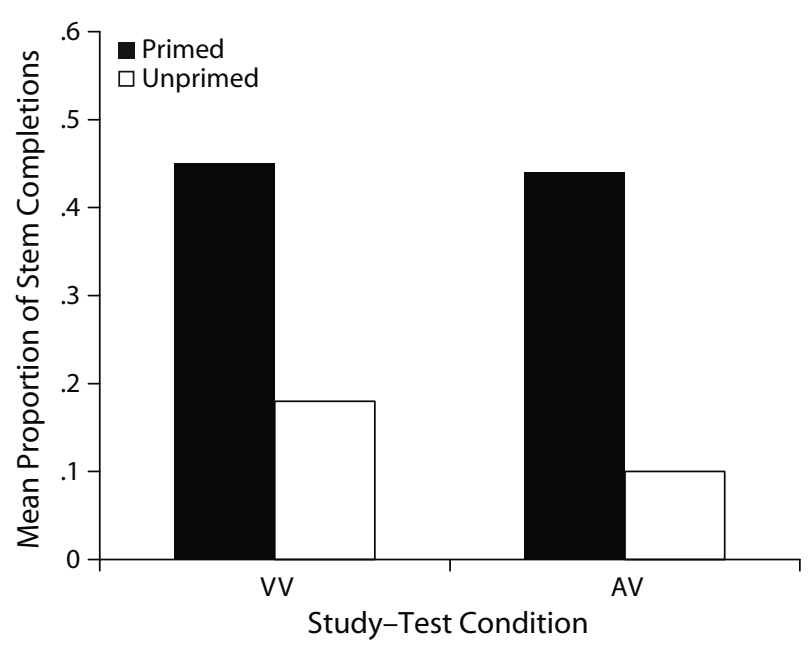

Figure 1. Mean proportions of stem completions as a function of study-test condition and priming in Experiment 1. V, visual; A, auditory. 
version of the test stems was introduced. An important constraint on critical words was the intelligibility and uniqueness of the word stem in spoken format. Care was taken to truncate each spoken word so as to produce a highly intelligible and faithful auditory word stem. This objective was achieved more easily for multisyllable words stressed on the first syllable, rather than on the second. Wherever possible, the word truncation was done by taking advantage of the natural boundary between the first and the second syllables. By doing so, the naturalness of spoken stems was increased, and the potential for disturbing after-clicks was diminished. The recordings were digitized with 16 bits per sample, using the SoundEdit 16 software.

In Experiment 2, each subset ( $a$ and $b$ ) consisted of 15 words (Appendix A). Otherwise, the experimental design was an extension of the design in Experiment 1. That is, it was a $2 \times 2 \times 2 \times 2$ design, with two priming conditions (primed or nonprimed), two modalities of test (visual or auditory), two modalities of study (same as test modality or different from test modality), and two subgroups. Group, test modality, and study were between-subjects factors; priming was a within-subjects factor. Typical visual and auditory test sequences approximated that depicted in Appendix B.

Procedure. The procedure paralleled the basic elements in Experiment 1 (study, questions about study, the interpolated U.S. presidents task, and test), with the additional requirement that at study (visual or auditory), the participant should generate an image for each study word. Closure of the study phase was achieved by having the participant give his or her quantitative and qualitative assessment of imagery he/she had performed (e.g., whether the participant's mental image was more frequently colorful or colorless, did the image include any sound or motion, and so on). These assessments were requested of 11 filler items; no imagery reports were requested of critical test items.

\section{Results and Discussion}

The results are summarized in Figure 2. Proportions of the mean correct stem completions per study-test condition were as follows: $\mathrm{AA}=.39$ (baseline $=.16)$, $\mathrm{VA}=$ .38 (baseline $=.17) ; \mathrm{VV}=.36$ (baseline $=.15), \mathrm{AV}=$ .38 (baseline $=.17$ ). The only significant factor was priming $\left[F_{1}(1,80)=188.8, p<.0001, P_{1}\right.$ (power) $=1.0$; $F_{2}(1,28)=75.5, p<.0001, P_{2}$ (power) $\left.=1.0\right]$. Neither test modality nor study (same modality as test or different modality from test) was significant $(F \mathrm{~s}<1)$, and neither of the modality $\times$ priming interactions (one involving test and one involving study) was significant $(F \mathrm{~s}<1)$.

The results of Experiment 2, obtained within a strictly implemented implicit memory design, suggest three major conclusions. First, cross-modal transfer occurs to the same degree in AV and VA. Second, AA transfer and VV transfer are of the same magnitude. Third, in corroboration of Experiment 1, transfer from study to test across modalities is equal in magnitude to transfer from study to test within a modality. The first and second conclusions are similarly suggested by the results of Bassili et al. (1989) and Habib and Nyberg (1997), but the third conclusion is not. That conclusion is uniquely drawn from the present results. Importantly, for the primary goal of the present research, the three conclusions for Experiment 2 run counter to the experimental observations that had led Morton (1979) to the hypothesis of separate lexicons for words seen and words heard.

There was no enhancement of VV performance level (relative to Experiment 1), as might have been expected if imagery activity at study induced an explicit, rather than implicit, memory strategy. To the contrary, performance was uniformly lower. The similarity of the results obtained in Experiments 1 and 2 suggests that the imagery instruction at the study phase in Experiment 2 did not produce any differential effect, relative to the passive "instruction" in Experiment 1, supporting the assumption that in Experiments 1 and 2, the participants performed within the framework of implicit memory experiments. Moreover, the similarity of the priming results above suggests that with or without orienting instructions at study, lexical involvement proceeds relatively automatically. The exception might be orienting instructions that specifically divert attention from word-level processing. The role of attention will be considered further in the Results and Discussion section for Experiment 3.

\section{EXPERIMENT 3}

Experiments 1 and 2 yielded three instances of equivalent intramodal and intermodal priming - for the commonly examined case of visual words at test in Experiment 1 and for both visual and auditory words at test in Experiment 2. To reiterate, the typical finding is that intramodal transfer is superior to intermodal transfer. An obvious question, therefore, is what makes the present experiments so different? The complementary question is perhaps of larger practical importance: What specific changes to the general design of Experiments 1 and 2 would yield the typically observed intramodality superiority?

Experiments 1 and 2 were conducted in accordance with the steps identified in the introduction. The identified steps were intended to promote comparable intramodal study and intermodal study and comparable intramodal test and intermodal test. Presumably, it was these steps, either singly or in combination, that led to the equivalence of cross- and intramodality performances. In the third experiment, in which AV was compared with VV, two of those steps were deliberately not taken. The experimental design was one in which the study modality was a withinsubjects variable and the instruction mode was more con-

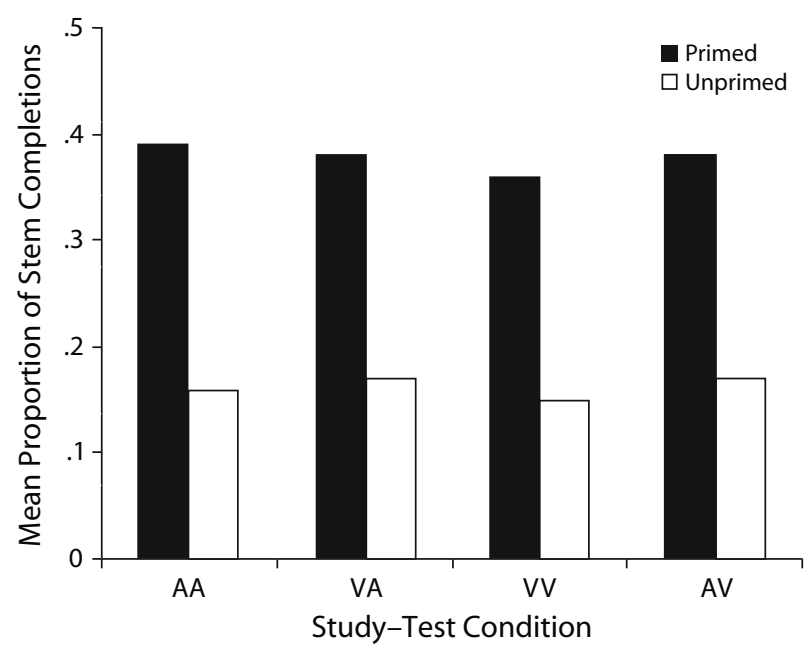

Figure 2. Mean proportions of stem completions as a function of study-test condition and priming in Experiment 2. A, auditory; $\mathbf{V}$, visual. 
sistent with study than with auditory study. A survey of the literature indicates that with rare exceptions, demonstrations of the superiority of VV over AV have been made using a within-subjects design. Such was the case for the influential Clarke and Morton (1983) study that was instrumental in forcing Morton (see Morton, 1979, 1980, 1982 ) to revise his theory from one logogen system to two logogen systems.

The results of Brown et al. (1991) and the analyses by Poulton (1982) suggest that a within-subjects design (that mixes the modalities) may introduce strategies that are different from those at work in a corresponding betweensubjects design. For example, when modalities are mixed, the participant's attention may be drawn to the modality differences between the words at study, with a coordinate reduction in attention to the phonology of the words. The match of modalities at test then exerts a relatively greater influence than in the corresponding between-subjects design. VV entails some level of lexical-phonological processing and modality-specific processing. In contrast, AV entails the same level of lexical-phonological processing, or so one could assume, but lacks the additional dimension of modality-specific processing. The consequence is poorer cross-modality than within-modality transfer.

\section{Method}

Participants. Forty-five undergraduates at the University of Connecticut participated in the experiment in partial fulfillment of an introductory psychology course requirement. The participants were assigned by order of appearance at the laboratory to one of three groups identified by the list of words presented at study (List A, List B, or List C), with 15 participants per group.

Materials. All study lists and the visual test list were identical to those used in Experiment 2.

Design. The base set of 30 critical words was divided into thirds: the $a$-subset, the $b$-subset, and the $c$-subset. Three experimental lists of 48 words -20 critical words and 28 filler words-were prepared for study. The lists differed only in the subsets of critical stimuli. List A included only the $a$ - and $b$-subsets, List B included only the $b$ - and $c$-subsets, and List $\mathrm{C}$ included only the $c$ - and $a$-subsets. In each study list, the first named subset was presented visually, and the second named subset was presented aurally. In each study list, the 10 visual critical words and the 10 auditory critical words were mixed randomly, along with the 28 filler words.

The same test list was given subsequent to the three study lists. It comprised 60 printed word stems, of which 30 were critical word stems. For each group of 15 participants, 20 critical stems had been primed-10 visually and 10 aurally-whereas the remaining 10 critical stems had not been primed. The remaining 30 word stems on the test list were fillers. The filler stems were unrelated to the filler words of the study list.

In sum, the design was $3 \times 3$, with three experimental lists crossed with three types of prime (visual, auditory, and no prime). The experimental conditions were AV, VV, and no-study-visual test. The last condition represented the performance on the unprimed critical subset and defined the baseline.

Procedure. Except for the mode of instruction, the phases of the experiment were identical to those in the visual test conditions in Experiment 2. In the between-subjects experiments (Experiments 1 and 2), the auditory study group of participants was instructed orally, whereas the visual study group received printed instructions. In the present experiment, and consistent with the typical procedure for the typical within-subjects design, all the participants received instructions in the visual mode. Paralleling Experiment 2, the words heard and the words seen at study had to be imagined. The modality of an upcoming trial was not signaled; for visual study, the loudspeaker remained on, and for auditory study, the screen remained lit. As in Experiment 2, closure of the study phase was achieved by having the participants report the mental images they generated for a subset of filler words.

\section{Results and Discussion}

The mean proportion of primed completions was .38 in $\mathrm{VV}$ and .30 in $\mathrm{AV}$, relative to the unprimed baseline of .15 . A $3 \times 3$ ANOVA ( 3 groups $\times 3$ prime types) revealed a reliable effect of priming $\left[F_{1}(2,84)=39.29, p<\right.$ $.0001, P_{1}$ (power) $=1.00 ; F_{2}(2,54)=23.73, p<.0001$, $P_{2}($ power $\left.)=1.00\right]$. A separate $3 \times 2$ ANOVA $(3$ groups $\times$ 2 prime types) clarified that $\mathrm{VV}$ was superior to $\mathrm{AV}$ $\left[F_{1}(1,42)=7.56, p<.01, P_{1}(\right.$ power $)=.78 ; F_{2}(1,27)=$ $5.38, p<.03, P_{2}$ (power) $\left.=.60\right]$. In neither ANOVA were any other factors significant.

The expectation that the outcome of Experiment 3 might not replicate the common outcome of Experiments 1 and 2 was confirmed. The within-subjects design of Experiment 3 benefited transfer in the same-modality condition, relative to the cross-modality condition. This apparent dependence of relative performance in the two conditions on experimental design is in agreement with the observations of Brown et al. (1991).

In the introduction to the experiment, it was suggested that less transfer in the cross-modality condition could arise as a consequence of reduced attention to word phonology at study. If the mixing of visual and auditory presentations draws attention to aspects of modality processing per se and away from word processing, then at test, those critical word stems sharing modality processing with the primes are more likely to be completed. It has been argued (e.g., Weldon, 1991) that in long-term visual word priming with an indirect test, (1) lexical activity at study is necessary for positive study-to-test transfer (but not perhaps sufficient; see Mulligan, 2003) and (2) processing of surface details at study augments transfer, but only if there is a significant degree of lexical access. Assuming equal but incomplete lexical activation by visual and auditory primes at study, visual primes will be more effective at test (e.g., visual stem completion), given their enhancement by surface modality processing.

The foregoing account of the asymmetries manifest in the within-subjects design of Experiment 3 assumes not only that lexical activation at study is necessary for positive transfer, but also that lexical activation can vary in magnitude as a function of attention. The latter idea, expressed in terms of variable degrees of phonological encoding, receives support from the experiment of McClelland and Pring (1991) referred to above. Transfer was shown to be systematically greater for study conditions that permitted a systematically better opportunity to assemble word phonology. Other lines of research on long-term implicit visual word priming might be considered as providing additional support. When focused attention at study is experimentally manipulated, stem completion is enhanced by attended primes, but not by unattended primes (Crabb \& Dark, 1999). When level of attention at study is experimentally manipulated, word identification at test is 
better for the higher levels (Hawley \& Johnston, 1991). In the latter research, a word at study was presented between two digits. Attention level to the word was manipulated by having the participants name the word, sum the digits, or do either according to a subsequent cue.

The identified asymmetry and the account given of it are obviously tentative, but not unreasonable. It must be remarked, however, that focusing strictly on whether the study phase is manipulated between or within subjects is unlikely to yield a sufficiently general account. As was suggested in the introduction, other potential influences on the comparability of intra- and intermodality long-term priming warrant consideration. One possibility is that priming in the same modality can be superior to priming across modalities because of the characteristics of the studied words. The general importance of word characteristics for long-term priming has been underscored by the investigations of Brooks et al. (1999). They examined transfer from visual study to visual stem completion. For word comparisons of the kind legacy versus legend, they found that legacy at study would facilitate legacy as the completion of leg considerably more than legend at study would facilitate legend as the completion of leg Brooks et al. suggested that key to the priming of visual stem completion is whether the stem is pronounced the same in isolation and in the prime. The leg of legacy satisfies the sameness criterion, but not the leg of legend. As was noted in the introduction to the present article, the conclusion drawn by Brooks et al. was that word-specific factors may influence long-term priming more so than do the commonly identified factors, such as modality and the orienting task at study.

In an experiment with auditory stem completion, Pilotti, Gallo, and Roediger (2000, Experiment 3) manipulated visual and auditory study between subjects and found better performance for auditory study, contrary to the present Experiments 1 and 2. One possible source of the discrepancy between these between-subjects experiments is the choice of words. In Pilotti et al.'s experiment, the criteria for word selection did not include spelling-sound consistency in both directions. To the extent that the study list includes nonunique mappings from spelling to sound and vice versa, priming auditory stem completion by written forms might be compromised, relative to priming auditory stem completion by spoken forms. Lukatela, Frost, and Turvey (1999) found that written words supporting more than one phonological interpretation, such as bowl, exhibited less short-term repetition priming than did phonologically consistent words, such as bend. This outcome was consistent with the hypothesis that the time required for a word's phonology to cohere sets the lower limit on visual word recognition latency. In long-term priming involving visual study, the apparently less direct emergence of phonology in the case of inconsistent words may have subtle consequences for the test phase. In particular, relative to the processing of consistent words, the competing phonological forms in the processing of an inconsistent word at study might impress themselves adversely upon the task of completing the word's auditory stem at test.

\section{EXPERIMENT 4}

Experiment 4 addressed whether the equivalence of inter- and intramodality transfer in the between-subjects design would replicate when the indirect test was fragment completion, rather than stem completion. The experiment compared AV with VV in a design that paralleled that in Experiments 1 and 2. There were two contrasting forms of incidental study: deep and shallow. Imaging the referent of a word was the deep case. The shallow case was counting the ascenders and descenders in a printed word or repeating out loud the spoken word.

\section{Method}

Participants. Ninety-six undergraduates at the University of Connecticut participated in the experiment in partial fulfillment of an introductory psychology course requirement. Each participant was assigned randomly to one of eight groups, with 12 participants in each group.

Materials. A subset of 32 critical words was identified, of which 30 had been used in Experiments 1-3 (see Appendix A). The 34 study fillers and the 32 test fillers were composed primarily from the base set identified in Experiment 1. The constraint on the visual word fragments was that they relate with approximately equal transparency to their target words in auditory and visual form.

Design. The set of 32 critical words was divided into two halves: the $a$-subset and the $b$-subset. Two experimental lists of 50 words were prepared for study that differed only in the subset of critical stimuli; List A included only the $a$-subset, and List B included only the $b$-subset. The combination of experimental lists and study modalities defined four groups of participants: visual-study-A-visualtest, visual-study-B-visual-test, auditory-study-A-visual-test, auditory-study-B-visual-test. At test, all four groups were presented with the same 64 word fragments, which included the 32 critical word fragments and the 32 test filler fragments. For each group at test, therefore, 16 critical fragments had been primed by study, and 16 had not. For each participant in each group, fragment completion of the primed critical fragment yielded the participant's transfer measure, and fragment completion of the unprimed critical stems yielded the participant's baseline measure of fragment completion performance.

The manipulations above led to a $2 \times 2 \times 2 \times 2$ design, with two priming conditions (primed or nonprimed), two modalities of study (same as test modality or different from test modality), two levels of study (deep or shallow), and two subgroups. The priming condition was a within-subjects factor, whereas group and study modality were between-subjects factors.

Procedure. The participants were tested individually. The participants assigned to visual study read all the instructions on the screen of the monitor, whereas the participants assigned to auditory study received all the instructions from the loudspeaker. The instructions for deep study were the same imagery instructions as those used in Experiment 2. The instructions for shallow study differed for the two modalities. Visual study participants were instructed to total the number of descending and ascending letters in a word. (For example, the word participant has two ascending letters and two descending letters, for a total of four.) Auditory study participants were instructed to listen to and repeat back each word.

All the participants were informed that the purpose of the study session, either visual or auditory, either deep or shallow, was to collect data for future research. No mention was given of a subsequent phase that could involve some of the same words as those presented at study. As in Experiments 1-3, the study phase was followed by the interpolated U.S. presidents' names task.

At the test phase, each participant received a written instruction that explained the fragment completion procedure. The participants 
were informed that $20 \mathrm{sec}$ were available for each fragment completion and that they should type into the keyboard the first word that came to mind that successfully completed the fragment. After $20 \mathrm{sec}$, a warning signal would sound, and the next trial would start.

\section{Results and Discussion}

A completion was scored as correct only if it exactly matched the target word. For deep study, the mean proportions of primed completions and nonprimed completions were .55 and .27 , respectively, for VV and .44 and .19, respectively, for AV. For shallow study, the mean proportions of primed completions and nonprimed completions were .50 and .26 , respectively, for VV and .46 and .20, respectively, for AV. The results are shown in Figure 3.

A 2 (processing depth) $\times 2$ (study modality) $\times 2$ (priming) $\times 2$ (group) ANOVA was conducted on the data. The three-way interaction of priming with processing depth and study modality (same as test modality or different from test modality) was not significant $\left[F_{1}(1,88)=1.30\right.$, $p>.05, P_{1}$ (power) $=.19 ; F_{2}(1,30)=0.59, p=.45$, $P_{2}$ (power) $\left.=.11\right]$. The only reliable effects were priming $\left[F_{1}(1,88)=404.88, p<.0001, P_{1}\right.$ (power) $=1.0$; $F_{2}(1,30)=99.63, p<.0001, P_{2}$ (power) $\left.=1.0\right]$ and study modality $\left[F_{1}(1,88)=12.73, p<.001, P_{1}\right.$ (power) $=.96$, $F_{2}(1,30)=19.21, p<.0001, P_{2}($ power $\left.)=.99\right]$.

Experiment 4 replicated with fragment completion what Experiments 1 and 2 had shown with stem completion: Cross-modality priming is of the same magnitude as within-modality priming. This replication with fragment completion suggests that the theoretically important result of Experiments 1 and 2 is not idiosyncratic to a specific indirect test.

The failure to find an influence on long-term priming of level of processing at study suggests that the processing tasks were alike in lexical involvement (Gardiner, RichardsonKlavehn, Ramponi, \& Brooks, 2001; Richardson-Klavehn \& Gardiner, 1998). The degree to which study tasks allow lexical processing can be expected to affect the degree to which study transfers to such tests as stem and fragment

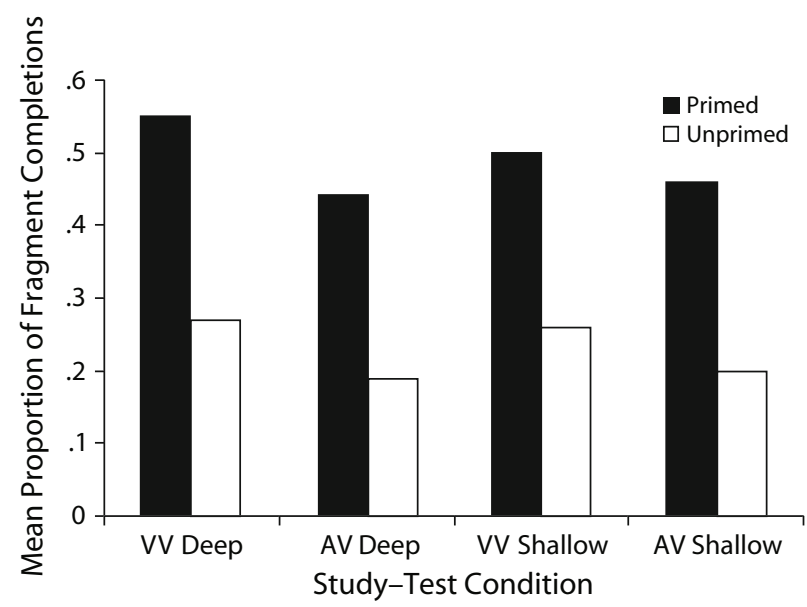

Figure 3. Mean proportions of visual fragment completions as a function of task at study, modality at study, and priming. The data are from Experiment 4. V, visual; A, auditory. completion (Gardiner et al., 2001). It would seem, therefore, that the two so-called deep study conditions and the two so-called shallow study conditions permitted equal degrees of lexical processing. The foregoing remarks reinforce the need for caution in interpreting previous designations of orienting tasks as shallow or deep. The benchmark for word stimuli may simply be whether the orienting task engenders lexical activation. It is "shallow" if it does not, and "deep" if it does.

A potentially puzzling aspect of the data in Experiment 4 is the modality-dependent proportion of correctly completed word fragments despite the modalityindependent size of priming. The latter pattern was not observed in the corresponding stem completion experiments (1 and 2). Comprehending the aforementioned "puzzling aspect" benefits from a focus on the unprimed baseline performance. Why should visual study in Experiment 4 have resulted in higher completion of unprimed visual word fragments, relative to auditory study? By design, the total set of words (primed and unprimed) was the same in both study conditions, and, by definition, the unprimed fragments were absent in both study conditions. Obviously, the superior cross-modality unprimed baseline could not have arisen from an advantage that was specific to the particular words experienced at study. A general advantage seemed to have been at play, probably strategic and probably emergent during the test phase. Conjecturing from Poulton's (1982) framework, the strategy used for completing visually primed fragments was carried over, asymmetrically, to completing unprimed fragments. As is shown and summarized in Figure 3, Experiment 4 suggests that in the present fragment completion tasks, an interesting dichotomy between magnitude of priming and the modality effect appeared: The magnitude of priming was independent of stimulus modality, whereas the overall magnitude of fragment completion was modality dependent. It is tempting to assume that this dichotomy reflects two different but co-occurring processes in implicit memory tasks: modality-independent lexical access and modality-dependent sensory analysis (see the General Discussion section).

A number of authors have pointed to the simultaneous contribution of these two processes to long-term priming (e.g., Jackson \& Morton, 1984; Jacoby, 1983; Tulving, 2001; Weldon, 1991). In particular, the unprimed baseline puzzle in Experiment 4 was anticipated in the research of Jackson and Morton (1984). Their experiment compared AA transfer and VA transfer, with perceptual identification in noise as the test. The experiment's design was a rare exception to the conventional design for implicit long-term priming: It was between subjects for study and within subjects for test. Words were divided into experimental and baseline. The two subsets were matched as closely as possible in word frequency and number of phonemes. At study, only experimental words were presented. They were presented in six conditions, each involving a different group of participants. At test, both experimental words and baseline words were randomly interleaved and presented to each participant. There was substantial priming of experimental words. There were also large dif- 
ferences in performance on the baseline words over the different study conditions. The differences among the primed words as a function of study were paralleled by the differences in performance on the baseline words in the different priming conditions (see Jackson \& Morton, 1984, Table 1). Jackson and Morton hypothesized that a possible reason for discrepancies between the groups of participants on the baseline words was that some general factor had been learned that applied to both experimental and baseline words. The authors did not expand on the nature of that "general factor."

\section{EXPERIMENT 5}

The claim of inferior cross-modality priming made by Morton and colleagues was based on results from experiments in which perceptual identification was used in the test phase. In the present Experiments 1-4, stem and fragment completion-indirect tests that have been repeatedly used in replications of inferior cross-modality transfer-were used to dispute the claim. For completeness, in Experiment 5, the two within-modality conditions and the two cross-modality conditions were investigated with perceptual identification as the form of the indirect test. There are good reasons for supposing that perceptual identification is a more reliable basis than stem and fragment completion for assessing implicit memory (Buchner \& Wippich, 2000).

In Clarke and Morton's (1983) experiment employing a within-subjects design, participants named near-threshold presentations of written words. The mixing of study conditions might have incurred Poulton's (1982) asymmetrical transfer. In Jackson and Morton's (1984) experiment employing a between-subjects design, participants had to identify, in writing, words spoken in background noise. This mixing of modalities might similarly have incurred Poulton's asymmetrical transfer. In Experiment 5, the conditions of study and test were chosen in such a way as to lessen the likelihood of asymmetrical transfer and were implemented in a between-subjects design.

Aside from completeness, the introduction of the perceptual identification task in Experiment 5 served an additional purpose. A challenge for investigations of the implicit-explicit distinction is determining whether implicit memory phenomena are contaminated by explicit memory processes (e.g., Butler \& Berry, 2001; Mitchell $\&$ Bruss, 2003). Was the equivalence of within- and crossmodality transfer in the present research due to inadvertent mediation by explicit recollection? Did the participants, purposely or unknowingly, use explicit recollection of the words encountered at study to mediate performance at test? There is an impression that contamination by intentional retrieval strategies is less probable in masked word identification than in other commonly used indirect tests (e.g., MacLeod \& Masson, 1997).

In addition to adoption of masked word identification at test, four special steps were taken in Experiment 5 to reduce and control contamination and to assess the degree to which it was involved (Butler \& Berry, 2001; Roediger $\&$ Geraci, 2005). First, the poststudy discussion of images generated during study was extended and refined so as to bias the participant's poststudy attention and memory toward the filler stimuli. Second, the critical words presented at study constituted only $20 \%$ of the words at test. Third, following the test phase, the participant was requested to recall in writing the words presented during study. Fourth, on completion of the experiment, the participant had to answer a questionnaire about relations between details of the separate tasks and his or her strategies at test.

\section{Method}

Participants. Ninety-six undergraduates at the University of Connecticut participated in the experiment in partial fulfillment of an introductory psychology course requirement. Each participant was assigned randomly to one of eight groups, with 12 participants in each group.

Materials. A basic set of 152 concrete words was assembled. A subset of 52 critical words was identified, of which almost one half were used in Experiments 1-4. Twenty-two words were designated as study fillers, and the remaining 78 words were assigned the role of test fillers. Assembled words were supposed to be consistent in both directions: from orthography to phonology and vice versa. These words were used for construction of both visual stimuli and auditory stimuli. Visual words were printed in Times New Roman font. The speech waves were digitized (with 9 bits per sample and $16 \mathrm{kHz}$ sampling frequency) and stored in the computer memory. Duration of the speech waves was equal to or less than $825 \mathrm{msec}$.

Both the visual and the auditory stimuli were prepared in two versions: noisy and noise free. In the visual noisy version, printed words were overlaid by a dense, random pattern of bright dots. The average dot density was calculated to cover $90 \%$ of a rectangular surface that could accommodate the longest printed word (e.g., hummingbird). The random pattern of bright dots for each successive trial was calculated and generated anew. The auditory noisy version was constructed by superimposing a pink noise wave of $825 \mathrm{msec}$ duration on the speech signal. The noise-to-signal ratio was kept at $6 \mathrm{~dB}$.

Design. The methodological steps identified in the introduction and applied to Experiments 1-4 were applied to Experiment 5. The base set of 52 critical stimuli was divided into two halves: the $a$-subset and the $b$-subset. Two experimental lists of 48 words were prepared for study that differed only in the subset of critical stimuli: List A included only the $a$-subset, and List B included only the $b$-subset. The combination of experimental lists and study modalities defined four groups of participants: visual-study-A-visual-test, visual-studyB-visual-test, auditory-study-A-visual-test, and auditory-study-Bvisual-test. At test, all four groups were presented with the same 130 words, which included the 52 critical words and 78 test fillers that were unrelated to the filler words at study (Appendix C). For each group at test, therefore, 26 critical noise-embedded stimuli had been primed by study, and 26 had not. For each participant in each group, the perceptual identification of the primed critical words yielded the participant's transfer measure, and perceptual identification of the unprimed critical words yielded the participant's baseline measure of identification performance.

Procedure. The participants were tested individually. Those assigned to visual study read their instructions from the monitor screen; those assigned to auditory study received their instructions through a headset. The participants were informed that the experiment would consist of different tasks that are popular in experimental psychology. At study, the participant was instructed to create a mental image of each presented word. The study list always started with a sequence of 11 filler words and was terminated with another sequence of 11 different filler words. Twenty-six critical words were presented in a random sequence (which was different for each participant) sandwiched between the initial and final sequence of 11 filler words.

In the case of visual study, a trial consisted of a $300-\mathrm{msec}$ fixation display (a pair of asterisks), followed by a 6-sec presentation of a printed word. In the case of auditory study, a trial consisted 
of a 1-sec buzz, followed by a rapid repetition of a spoken word of maximally $825-\mathrm{msec}$ duration. In both study modalities, the interval between trials was $5 \mathrm{sec}$, and the trial duration approximated $12 \mathrm{sec}$. On completion of the 48 study trials, the participant and experimenter engaged in a 10-min discussion in which the experimenter invited the participant to describe in detail the participant's mental images of 8-10 different words identified by the experimenter and selected from the study fillers. After the study session, each participant received the interpolated U.S. presidents task and, on termination, an appraisal by the experimenter of the participant's capability to remember personal names. The test phase with noise-embedded words then began.

There were 130 words on the test list. To reiterate, each visual word was presented for $200 \mathrm{msec}$ (at the center of the monitor), and each auditory word was presented twice at $825 \mathrm{msec}$. The first 22 words were always designated as practice. For the 22 visual practice words, the dot density was gradually increased from $60 \%$ up to $90 \%$. For the 22 auditory practice words, the noise-to-signal ratio was gradually increased from $3 \mathrm{~dB}$ up to $6 \mathrm{~dB}$. The remainder of the list (presented with $90 \%$ dot density or 6-dB ratio) consisted of 26 studied words, 26 unstudied words, and 56 test fillers, with any 2 studied critical words separated by at least 2 unstudied words.

For the visual test, the participant's written instruction explained that $20 \mathrm{sec}$ were available to enter (by the keyboard) the identified word or the first word that came to mind. By pressing the space bar, the trial was terminated. If the space bar was not pressed within $20 \mathrm{sec}$, a warning signal sounded, and the next noise-embedded word was presented (regardless of the missing response).

In the auditory test, the participant's oral instruction explained that $20 \mathrm{sec}$ were available for verbal identification of the twice-presented noise-embedded spoken word. The participant was to say aloud the identified word or the first word that came to mind. If verbal identification did not occur in $20 \mathrm{sec}$, a warning signal sounded, and the next noise-embedded word was presented.

The task sequence of study, then presidents' names, and then test was terminated by a memory assessment and a questionnaire. The participant was requested to write down the words seen or heard during the study phase. No memory cues were given. Of the 48 studied words, only the 26 critical words were accepted as hits. Finally, the participant provided in writing the answers to six questions that were printed on two separate pages (Appendix D). On the first page of the questionnaire, there were four open-ended questions. Two closeended questions (5 and 6 ) were printed on the second page. The participant could read Questions 5 and 6 only after Questions 1-4 had been answered. In total, the experiment lasted approximately $50-60 \mathrm{~min}$.

\section{Results and Discussion}

A perceptual identification was scored as correct only if it matched the target word exactly. (The one exception to the rule was the suffix morpheme $s$.) In the visual test, the aforementioned criterion meant a correct spelling of written responses. In the auditory test, the aforementioned criterion meant that all phonemes had to match those of the spoken word (local dialect variations were accepted).

Study-test manipulations. The results are summarized in Figure 4. Proportions of the mean correct perceptual identifications per study-test condition were the following: $\mathrm{AA}=.54$ (baseline $=.37$ ), $\mathrm{VA}=.44$ (baseline $=.33) ; \mathrm{VV}=.56$ (baseline $=.43)$, and $\mathrm{AV}=.47$ (baseline $=.35$ ). An inspection of Figure 4 suggests no interaction between priming and study-test condition. Confirmation was provided by an ANOVA with the factors of priming (primed or unprimed) $\times$ test (visual or auditory) $\times$ study (same modality as test or different modality from test $) \times$ group. There were main effects of

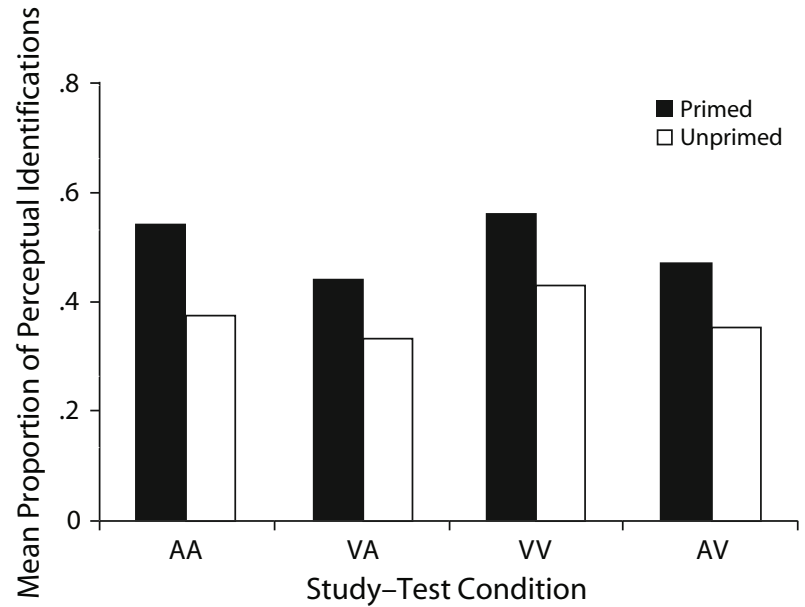

Figure 4. Mean proportions of perceptual identifications as a function of study-test condition and priming in Experiment 5. A, auditory; V, visual.

priming $\left[F_{1}(1,88)=93.64, p<.0001, P_{1}\right.$ (power) $=1.0$; $F_{2}(1,50)=86.69, p<.0001, P_{2}($ power $\left.)=1.0\right]$ and study $\left[F_{1}(1,88)=9.32, p<.01, P_{1}(\right.$ power $)=.87 ; F_{2}(1,30)=$ $29.05, p<.0001, P_{2}$ (power) $=1.0$ ], with no interactions (all $F \mathrm{~s}<1$ ). Given the commonplace finding of samemodality superiority, the $6 \%$ superiority of AA over VA was evaluated separately. The ANOVA restricted to auditory tests showed priming $\times$ study to be significant only by items $\left[F_{2}(1,50)=4.10, p=.05, P_{2}\right.$ (power) $\left.=.50\right]$. The results of Loveman, van Hooff, and Gale (2002) suggest that this weak effect might reflect the benefits in AA of speaking aloud both study items and test responses.

Memory test. Following the test phase, the participants were asked to recall words encountered in the study phase. The question of interest was the number of recallable study words that belonged to the set of target words- that is, the primed test words. On average, the participants recalled 3.2 of the 26 critical words (the primes). In contrast, the participants recalled, on average, 7.7 of the 22 filler words presented at study. The superior recall of the filler words were likely due to the facts that (1) the study fillers were assigned to the first 11 and to the last 11 stimuli on each study list and (2) approximately 50\% of the study fillers were discussed explicitly by the participant and the experimenter on conclusion of the study phase. It will be recalled that the purpose of (2) was to bias the participant's poststudy attention and memory toward the filler stimuli.

Questionnaire. The questionnaire was intended to assess awareness of the relation between test and study and the equation of that awareness with the use of an explicit retrieval strategy. To reiterate, studied words constituted only $20 \%$ of the words at test. The high 5:1 ratio of unstudied to studied words at test was for the purpose of reducing test awareness (Butler \& Berry, 2001; Roediger \& Geraci, 2005; Roediger \& McDermott, 1993).

Question 3 asked whether there was any connection between the three tasks. Approximately $85 \%$ of the participants answered affirmatively. Question 4 inquired about the strategy used when identifying the masked words at 
test. Approximately $70 \%$ identified their strategy as trying to ignore or attenuate the noise impeding perception of the word (e.g., by head movements when hearing or by squinting when looking). Question 6 inquired whether the participant used knowledge of words from Task A (study) to facilitate performance of Task C (test). Approximately 85\% answered "yes." Only 3 participants, however, elaborated on their positive answer. They claimed that they had tried to develop an expectation strategy on the basis of what they remembered from study.

The test responses were analyzed for insight into the potential contradiction between the answers to Questions 4 and 6. The analysis was limited to VV and AV. In the visual test, all of a participant's test responses were typed (by the participant) into the computer. With the 22 practice presentations at test excluded, a participant had 108 opportunities to make an identification response. Focusing upon the $\mathrm{AV}$ group, the average participant was correct on $49 \%$, wrong on $8 \%$, and failed to make any response (in the allotted 20 -sec interval) on $43 \%$, of the 108 presentations (a similar pattern held for the VV group). The $49 \%$ correct identification responses were composed of $11 \%$ to the 26 primed critical words, $9 \%$ to the 26 unprimed critical words, and $29 \%$ to the 56 filler words. The $8 \%$ incorrect word identifications at test came from three primary sources. Words that appeared only in the test list constituted $2 \%$ of the wrong responses; words that appeared in the study list constituted $1 \%$; and words from neither list constituted 5\%. An examination of the erroneous words from the study list revealed that the majority were fillers - in particular, the words that constituted the first 11 and last 11 words on the study list (see the Memory Test section above). Only a third of the $1 \%$ response errors drawn from the study list were critical words - that is, words that were included in both the study and the test lists.

The analysis of test responses reveals that the participants were not biased to responding with studied critical words. Of the 62 identification responses made on average, only about 12 , on average, were studied critical words. Furthermore, when a study word was given as a wrong identification, it was more likely to have been a filler word than a critical word. The greater frequency of study fillers as errors was to be expected. Study fillers benefited from primacy and recency effects, as well as from explicit rehearsal, during the imagery elaboration immediately subsequent to study.

It is noteworthy, however, that despite the bias toward remembering study fillers, they were not the dominant errors. Nonstudied words were five times more common as incorrect identifications. The implication is that perceptual information governed test performance (as is suggested by the majority's answer to Question 4), rather than efforts to recall words from study. There are two further implications. First, awareness that study words were in the test list could have originated from (and/or been amplified by) incorrect identifications-for example, by identifying a noise-embedded word incorrectly as one of the well-remembered initial 11 or final 11 filler words. Second, if word features detected in the noise sufficed to suggest a study filler or a recently typed or spoken test word, it might be inferred that the participants used that information to constrain the identification response (compare with Kinoshita, 2001).

In sum, the questionnaire analysis gives no reason to suppose that the average participant adopted an intention at test to retrieve studied words (see Richardson-Klavehn \& Gardiner, 1995, 1996, 1999). There is no contradiction between the answers to Questions 4 and 6. The participant tried to suppress the noisy background of a test word (answer to Question 4) and, when possible, used recalled words from previous parts of the experiment to help identify a test word (answer to Question 6). The modality effect of the present experiment may be corroborative of the conclusion implied by the questionnaire data. The effect is typically taken to mean that explicit recall is only weakly involved in the observed study-to-test transfer.

\section{GENERAL DISCUSSION}

The common finding that long-term priming is better when study and test are in the same modality, as opposed to between modalities, has been used to motivate theory on two important issues: the nature of the mental lexicon and the distinction between implicit and explicit memory. We should expect, therefore, that our results—showing equivalence of intra- and intermodality priming-have consequences for both issues. In a nutshell, they suggest that (1) there is a single lexicon serving word identification by both ear and eye and (2) modality independence characterizes implicit, as well as explicit, memory.

One departure point for evaluating Conclusions 1 and 2 is the view that long-term word priming is an incidental by-product of the general perceptual-learning capability adapted to the demands of acquiring and identifying words (Bowers \& Kouider, 2003). This view is advanced as an alternative to the more commonplace memory-based view, of which TAP is a prominent representative. We will argue that the larger lesson of Conclusions 1 and 2 is that the account of long-term word priming requires an integration of the two views, but in revised forms.

\section{The General System for Learning and Identifying Words}

To date, efforts to embed the data on long-term priming in a model of visual word recognition have been guided primarily by the interpretation that the lexicon of relevance comprises (whole-word) orthographic representations (Bowers \& Kouider, 2003). On this interpretation, the commonly reported superiority of $\mathrm{VV}$ over AV is easily rationalized: Print primes print better than sound primes print. The primary implication of the present research, however, is that prior observations of nonequivalence of intra- and intermodality priming might have been due to methodological artifact. In Experiment 3, the nonequivalence arose within the combination of a within-subjects design and instructions presented in the modality of the test phase. In Experiments 1 and 2 and Experiments 4 and 5-with between-subjects designs and modality of instructions conforming to modality of study-different-modality primes were equally as effective as same-modality primes. 
The sameness of within-modality and cross-modality transfer and, importantly, the indifference of this "sameness" to cross-modal direction (visual to auditory and auditory to visual) seem to require an interpretation of the relevant lexicon as phonological, rather than orthographic. Proponents of the view that implicit long-term priming reflects ordinary aspects of the visual word recognition system contend that the lexical code must be abstract in order to accommodate the multiplicity of written and printed optical forms that words assume (e.g., Bowers \& Kouider, 2003). The most obvious and linguistically significant invariant underlying a word's multiple optical forms is the phonology that the forms specify (Lukatela \& Turvey, 1990, 1998).

The upshot of the foregoing is that if the theory of longterm visual word priming is to be anchored in a system for learning and identifying words, it seems advisable to emphasize the primacy of phonology, rather than orthography, in the functioning of that system. Other experiments point to the same conclusion (e.g., Brooks et al., 1999; Rueckl \& Mathew, 1999). Of significance to this suggested revision - and of relevance to identifying the phonology in question - are observations that phonetic length affects visual lexical decision. The acoustic duration of spoken monosyllabic words is longer if the consonant following the vowel is voiced (e.g., /d/), rather than voiceless (e.g., /t/; see e.g., Port, 1979, 1981). This distinction in phonetic length is manifest in visual recognition as a longer latency to printed words such as plead, relative to printed words such as pleat (Abramson \& Goldinger, 1997; Lukatela, Eaton, Sabadini, \& Turvey, 2004). Reading a word engages a phonological form that represents not only phonologically significant distinctions of traditional concern, but also physical phonetic details. That is, the mediating phonology may comprise both categorical (discrete) distinctions and gradient (continuous) distinctions.

Among contemporary phonologies, the phonology most befitting the latter characterization is gestural or articulatory phonology (Goldstein \& Fowler, 2003; Lukatela et al., 2004). The primitives of gestural phonology are gestures and constellations of gestures of the vocal tract, where a gesture is a characteristic movement pattern of vocal tract articulators and a gestural constellation is a small number of potentially overlapping gestures composing an utterance. Because a word's representation in gestural phonology is composed of dynamical systems (functional synergies) and their phase relations, it incorporates information about the temporal coordination of the gestures that express consonants and vowels (Saltzman \& Munhall, 1989). In gestural phonology, there is no phonetic-phonological gap. The low-dimensional cognitive phonology and the high-dimensional physical phonetics are complementary aspects of a single complex dynamical system.

To hypothesize that the representations underlying visual word recognition are gestural is to highlight the fundamental experiences with speaking and hearing words in the development of the system that learns and identifies words, whether auditory or visual. Those experiences, it can be supposed, fashion a gestural phonological lexicon that is used initially (early in one's development) in auditory word recognition and eventually (later in one's development) in both auditory and visual word recognition. An expectation that follows from the aforementioned supposition is the pattern of results of the present research: no significant priming differences between cross-modality and within-modality conditions and no significant priming difference between AV and VA cross-modality conditions.

\section{Principles of Transfer-Appropriate Processing and Encoding Specificity}

The recommended revision of TAP to accompany the suggested revision of the word-learning-and-identification system is that TAP constitutes a principle and methodology for exploring long-term priming, rather than a process model of long-term priming (Franks, Bilbrey, Lien, $\&$ McNamara, 2000). The shared processes that engender transfer from study to test are particular to the specifics of (1) the stimuli at study, (2) the stimuli at test, (3) the task constraints at study, and (4) the task constraints at test. The shared processes are not obligatory stages of fixed temporal sequence and/or hierarchical order (Franks et al., 2000).

The idea of TAP, as advanced originally by Morris et al. (1977), is a variant of a long-standing view that forgetting is a temporary state. McGeoch $(1932,1942)$ proposed that forgetting occurs to the degree that more than one past event is a competitive candidate at retrieval and to the degree that external context (environmental circumstances) and internal context (one's mind-set) change from original encoding to current retrieval. For McGeoch's temporary lapse view, if a person demonstrates memory for a fact or an event at time $t$, that memory is potentially retrievable at all subsequent times, providing the conditions at retrieval are appropriate (Neath \& Surprenant, 2003). TAP emphasizes McGeoch's internal context: Memory performance is maximized when study and test engage identical mental processes. In complementation, Tulving's ES principle (e.g., Tulving \& Thomson, 1973) emphasizes McGeoch's external context: Memory performance is maximized when study and test involve the same stimulus situation. As has been argued by Franks et al. (2000), the complementary principles of TAP and ES amount to the claim that the memory of an event or fact expresses "the unique interaction of a particular intentional act engaged with a particular stimulus situation" (p. 1140).

The findings of the present research underscore the methodological significance of the complementary TAP and ES principles. In the four between-subjects experiments, the "intentional act" and the amodal features of the "particular stimulus situation" in auditory and visual study were maintained as closely similar as possible. Too great a dissimilarity would have, by the TAP and ES principles, induced differential memory effects at test, inviting inferences of processing distinctions between words heard and words seen. At test, the intentional act did not replicate that at study. But as long as the disparity was of like kind and of equivalent magnitude for both auditory and visual study, the degrees of (submaximal) transfer should have 
been commensurate in the cross-modality and withinmodality conditions. As has been noted, commensurate transfer in the two conditions was indeed the case.

It is of some importance to note that the results of Experiments 4 and 5 did suggest a processing distinction between words heard and words seen, but not one related to word priming. The distinction allows the tentative hypothesis that the carryover from study to test occurs simultaneously along two dimensions, one that reflects the qualitative contrast between seeing and hearing and one that does not. As was intimated in the discussion of Experiments 4 and 5, the higher overall test performance in the VV conditions, as opposed to the AV conditions (see Figures 3 and 4), is a pure vision effect. That the performance advantage was the same for the primed and the unprimed words rules out beneficial transfer of graphic details of the study words and points to the qualitatively distinct activity of seeing words at study as the source of the VV advantage. Priming magnitude, on the other hand, is an amodal effect. Its invariance over $\mathrm{AV}$ and $\mathrm{VV}$ rules out the distinct sensory qualities of seeing words and hearing words and points to the activation of phonology as the dimension of transfer. A parallel account follows for the AA versus VA results of Experiment 5 (see Figure 4).

The modal dimension of transfer putatively evident in the data in Figures 3 and 4 is the limiting case of Jacoby's (1983) data-driven processes and Nairne's (1990) modality-dependent features. Beyond the qualitative character of seeing and hearing words are detailed specifics of the conditions of presentation. Seeing a printed word entails encoding font, case, size, and so on; hearing a word entails encoding the speaker's dialect, gender, loudness, and so on. We reiterate, however, that the basis for the overall superiority, shown in Figures 3 and 4, of $\mathrm{VV}$ over $\mathrm{AV}$ is not to be found in the latter details. It seems to reflect a more global process-at the level of the perceptual system, rather than at the level of its many component functions.

A possibility worthy of further investigation is that the often-reported modality-dependent priming effect (e.g., VV being better than AV) is a consequence of experimental designs that inadvertently intertwine the modal and amodal processes identified in the present research. Experiments 4 and 5 suggest that the processes can be disentangled by use of a between-subjects design and a test phase that involves either fragment completion or perceptual identification. Jackson and Morton (1984) may have taken the first step toward disentangling modalitydependent transfer at the perceptual system level and modality-independent transfer at the lexical access level. For those authors, what was revealed in their experiments was a general modality factor transferring from study to test in parallel with the transfer of stimulus-specific processing details responsible for priming.

\section{Morton's (1969) Hypothesis of a Single Lexicon Now Seems the Better Hypothesis}

Morton's original logogen model, shown in Figure 5, was the height of simplicity and parsimony. Its core comprised devices responsible for producing word-sized phonological codes whenever appropriate. For example, the word chair would entail activation of one and the same logogen when heard, seen, spoken in response to a question about the object's name, given as a free associate to the word table, or produced in spontaneous speech. The chair logogen was assumed to be responsible for all outputs of that particular word and, in addition, was identified as the point of coincidence for all inputs bearing on the output of that particular word. For the speaker in a conversation about furniture, the relevant input for activating the chair logogen would be semantic; for a listener, it would be acoustic.

Two predictions of the original model in respect to visual word identification at test were not upheld. First, naming a pictured chair at study proved to be a less effective prime than reading the word at study (Winnick \& Daniel, 1970; subsequently confirmed by Clarke \& Morton, 1983). Second, and as emphasized in the present article, hearing chair at study proved to be a less effective prime than seeing chair at study (Clarke \& Morton, 1983).

The first failed prediction led to the modification shown in Figure 6A. The original single logogen system was divided into two, one for input and one for output. The division separated the site of chair's facilitation (by the sight or sound of the word) from the source of chair's phonological code. Naming a picture was envisaged as a sequence of picture recognition in the cognitive system, followed by the issuing of a semantic code to the output logogens, followed in turn by the production of the picture's name. In Figure 6A, the coincidence of inputs referred to above is the province of the output system.

The second failed prediction, and suggestions that the failure held similarly for visual-to-auditory transfer (Jackson \& Morton, 1984), led to the modification shown in Figure 6B. The input, logogen system was split into two, one for visual inputs and one for auditory inputs, with the additional feature that the two input logogen systems do not communicate.

As can be summarized in a comparison of Figure 6B with Figure 5, the two failed predictions triggered an evolution of the logogen model. Adaptation to the unexpected and novel data required three logogen systems to perform the functions originally performed by one logogen system.

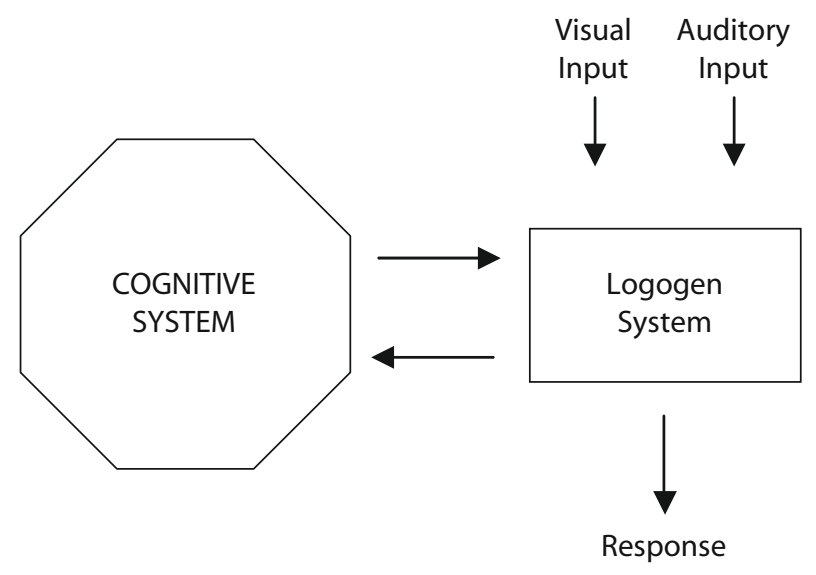

Figure 5. The original logogen model. 

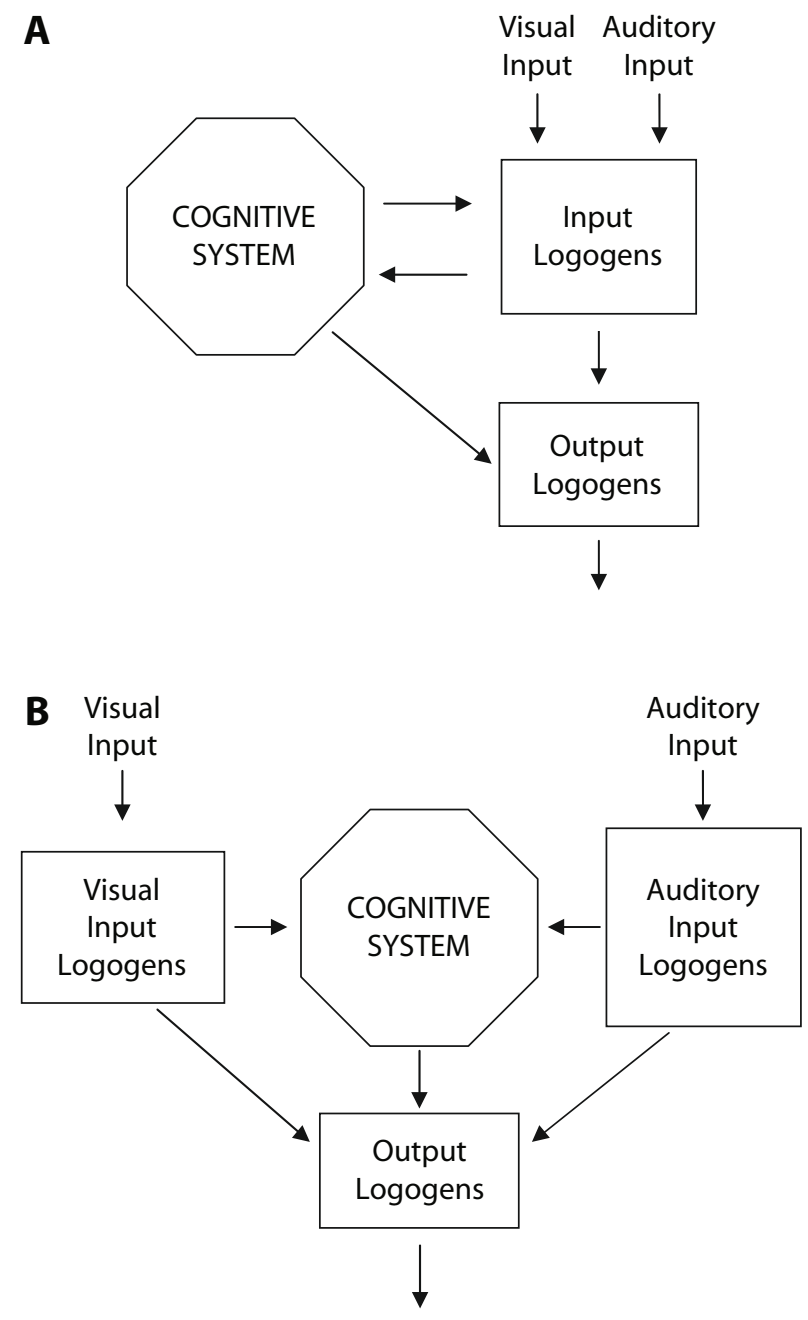

Figure 6. Evolution of the logogen model.

The present research suggests that this evolution may have been unnecessary. The model can devolve to Figure 6A and, possibly, to its original form. The equivalence of $\mathrm{AV}$ and VA transfer and the equivalence of both to withinmodality transfer (see Figures 2 and 4) eliminate the need for two input logogens but also suggest the nonnecessity of a division into input and output logogens.

The first failed prediction motivating the latter division may well be a methodological artifact, as the second failed prediction now seems to be. Brown et al. (1991) compared the transfer from naming pictures or words at study to naming words at test in a within-subjects design and in a between-subjects design. The influential result of Winnick and Daniel (1970) was replicated in the former design, but not in the latter design. When word study and picture study were manipulated within subjects, transfer was superior for word study. In contrast, when word study and picture study were manipulated between subjects, Morton's (1969) original prediction was confirmed: Transfer to the test phase in both conditions was significant and of equal magnitude.
In sum, there may be sufficient evidence to warrant a sincere reconsideration of the model depicted in Figure 5. A possible counter to this conclusion comes from singlecase neuropsychological studies. A patient with semantic and orthography-phonology coding deficits who was asked to say and then write (or write and then say) the name of a picture frequently failed to give the same name twice. If asked to name the picture twice in succession, but in the same mode (e.g., write it both times), the patient tended to be consistent, repeating the same name. It is argued that the preceding pattern of data suggests, in the manner of Figure 6B, autonomy of orthographic and phonological word forms (Miceli, Benvegnu, Capasso, \& Caramazza, 1997). Another patient who often failed to recognize spoken words could, nonetheless, recognize the same words in print, suggesting an orthographic-lexicon-to-meaning mapping that was intact and separate from an impaired phonologicallexicon-to-meaning mapping (e.g., Coltheart, 2004).

Circumspection is needed, however, in regard to the aforementioned cases and the conclusions drawn from them. Single-case studies are controversial (e.g., Grodzinsky, Piñango, Zurif, \& Drai, 1999; Robertson, Knight, Rafal, \& Shimamura, 1993), as is the doubledissociation logic that underwrites the interpretation of the data they provide (e.g., Dunn \& Kirsner, 2003; Juola \& Plunkett, 2000; Kello, 2003; Kinder \& Shanks, 2003; Plaut, 1995; Van Orden, Pennington, \& Stone, 2001). Implementing the dissociation logic rests on the assumption that the patient's "qualitative deviation from intact behavior (the effect) originates in damage to a specific isolable component or components of the brain (the cause)" (Colangelo, Holden, Buchanan, \& Van Orden, 2004, p. 151). Doubts about the assumption have been expressed in varied ways, from the lack of parsimony in explaining a bilingual deep dyslexic (Béland \& Mimouni, 2001), to the absence of reliable modularity-defining criteria (e.g., Farah, 1994; Uttal, 2001), to the claim that qualitative changes are more likely to reflect self-organizing interaction-dominant dynamics, rather than a malfunctioning of autonomous components (e.g., Colangelo et al., 2004; Kello, 2003; Van Orden, Jansen op de Haar, \& Bosman, 1997). Finally, the experimental method by which the impairments in single-case studies are revealed can also be questioned. For example, indirect tests portray a deep dyslexic patient differently than do direct tests (e.g., Buchanan, Hildebrandt, \& MacKinnon, 1999; Buchanan, McEwen, Westbury, \& Libben, 2003). Indirect tests reveal that access to the sublexical phonology of words and nonwords is preserved, rather than lost.

Returning to Figure 5 and the proposed single system for words by ear and by eye, it is worth highlighting that a single system is similarly proposed to underlie word identification in first-learned and second-learned languages (e.g., Van Wijnendaele \& Brysbaert, 2002). Phonology's leading role is at the core of both proposals. Consider a network whose nodes can represent phonological, orthographic, and semantic properties (e.g., Rueckl, 2002). Hearing and seeing a word, in either Language 1 or Language 2 , induces changes in the pattern of activation over 
the nodes, moving the network to attractor states specific to the phonological, orthographic, and semantic properties of the word.

Because the mappings of both the spoken word and the written word are more nearly one-to-one than are the acoustical-semantic, orthographic-semantic, and phonological-semantic mappings, the phonological form of a word is coded at the outset closest to its final form (Van Orden \& Goldinger, 1994). The quickly attained stability of the word's phonological code, whether in response to the word heard or seen, sets it apart from other codes. Within a single connectionist system, it is in the position of playing a key role in facilitating (mediating) the coherence and stability of the linguistic processes that the word stimulates.

The latter single-system conception-suggesting a common basis for hearing and seeing words, in both firstlearned and second-learned languages_-does not seem so far removed from Morton's original logogen conception expressed in Figure 5.

\section{A Caveat and Future Considerations}

A critical concern, in regard to the conclusions drawn, has to do with the precise reason that the present research produced results in contradiction to conventional understanding. At the current juncture, the precise reason is unclear. The issue of pure versus mixed study lists - the contrast of between-subjects and within-subjects designs-is certainly central to the contradiction. Curran, Schacter, and Galluccio (1999) admitted being puzzled by the finding that, for their normal participants, the intermodal priming that they investigated in their Experiment 2 was as substantial as the intramodal priming that they investigated in their Experiment 1. Curran et al. confronted the issue of the sensitivity of implicit memory to modality change outside the within-subjects design and failed to observe the expected inferiority of cross-modality priming.

As central as it may be, the between-subjects design that marks the present series of experiments cannot provide a complete account of the contradictory findings. A betweensubjects design does not guarantee an equivalence of interand intramodality priming (e.g., Jackson \& Morton, 1984; Pilotti et al., 2000). Other factors are at work, as was highlighted in the discussions of the present Experiments 3 and 4 (see also Loveman et al., 2002). The important lesson to be learned from the observation that the principles of TAP and ES are complementary is that a full account of any instance of implicit memory requires a thoroughgoing examination of the specifics of the stimuli at study and test and the specifics of the task constraints at study and test. The transfer from study to test depends on these specifics. The important lesson to be learned from the hypothesis that long-term word priming is grounded in phonology is that the transfer from study to test depends on how the aforementioned specifics impede or facilitate phonological processing at study and test. Future developments on the conjoint issues of the number of lexicons and the perceptual sensitivity of implicit memory will depend on how the two lessons above are implemented in theory and research.

\section{AUTHOR NOTE}

Preparation of this article was supported by National Institute of Child Health and Human Development Grant HD-01994 to the Haskins Laboratories. Correspondence concerning this article should be addressed to G. Lukatela, Haskins Laboratories, 300 George Street, New Haven, CT 06510 (e-mail: georgije.lukatela@ haskins.yale.edu).

\section{REFERENCES}

Abramson, M., \& Goldinger, S. D. (1997). What the reader's eye tells the mind's ear: Silent reading activates inner speech. Perception \& Psychophysics, 59, 1059-1068.

Bassili, J. N., Smith, M. C., \& MacLeod, C. M. (1989). Auditory and visual word-stem completion: Separating data-driven and conceptually driven processes. Quarterly Journal of Experimental Psychology, 41A, 439-453.

BegG, I., Snider, A., Foley, F., \& Goddard, R. (1989). The generation effect is no artifact: Generating makes words distinctive. Journal of Experimental Psychology: Learning, Memory, \& Cognition, 15, 977-989.

BéLAnd, R., \& Mimouni, Z. (2001). Deep dyslexia in the two languages of an Arabic/French bilingual patient. Cognition, 82, 77-126.

BLAXTON, T. A. (1989). Investigating associations among memory measures: Support for a transfer-appropriate processing framework. Journal of Experimental Psychology: Learning, Memory, \& Cognition, 15, 657-668.

Bowers, J. S., \& Kouider, S. (2003). Developing theories of priming with an eye on function. In J. S. Bowers \& C. J. Marsolek (Eds.), Rethinking implicit memory (pp. 19-40). Oxford: Oxford University Press.

Brooks, J. O., III, Gibson, J. M., Friedman, L., \& Yesavage, J. A. (1999). How to drastically reduce priming in word stem completionand still present the words. Memory \& Cognition, 27, 208-219.

Brown, A. S., \& Mitchell, D. B. (1994). A reevaluation of semantic versus nonsemantic processing in implicit memory. Memory \& Cognition, 22, 533-541.

Brown, A. S., Neblett, D. R., Jones, T. C., \& Mitchell, D. B. (1991). Transfer of processing in repetition priming: Some inappropriate findings. Journal of Experimental Psychology: Learning, Memory, \& Cognition, 17, 514-525.

Buchanan, L., Hildebrandt, N., \& MacKinnon, G. E. (1999). Phonological processing in acquired deep dyslexia reexamined. In R. M. Klein \& P. A. McMullen (Eds.), Converging methods for understanding reading and dyslexia (pp. 191-220). Cambridge, MA: MIT Press.

Buchanan, L., McEwen, S., Westbury, C., \& Libben, G. (2003). Semantics and semantic errors: Implicit access to semantic information from words and nonwords in deep dyslexia. Brain \& Language, 84, 65-83.

BUCHNER, A., \& WiPPICH, W. (2000). On the reliability of implicit and explicit memory measures. Cognitive Psychology, 40, 227-259.

BURNS, D. J. (1992). The consequences of generation. Journal of Memory \& Language, 31, 615-633.

BUTLER, L. T., \& BERRY, D. C. (2001). Implicit memory: Intention and awareness revisited. Trends in Cognitive Sciences, 5, 192-197.

Challis, B. H., \& Brodbeck, D. R. (1992). Level of processing affects priming in word fragment completion. Journal of Experimental Psychology: Learning, Memory, \& Cognition, 18, 595-607.

Clarke, R., \& Morton, J. (1983). Cross-modality facilitation in tachistoscopic word recognition. Quarterly Journal of Experimental Psychology, 35A, 79-96.

Colangelo, A., Holden, J. G., Buchanan, L., \& Van Orden, G. C. (2004). Speculation about behavior, brain damage, and selforganization: The other way to herd a cat. Brain \& Language, 90, 151-159.

Coltheart, M. (2004). Are there lexicons? Quarterly Journal of Experimental Psychology, 57A, 1153-1171.

Coltheart, M., Rastle, K., Perry, C., Langdon, R., \& Ziegler, J. (2001). DRC: A dual route cascaded model of visual word recognition and reading aloud. Psychological Review, 108, 204-256.

Crabb, B. T., \& Dark, V. J. (1999). Perceptual implicit memory requires attentional encoding. Memory \& Cognition, 27, 267-275. 
Curran, T., Schacter, D. L., \& Galluccio, L. (1999). Cross-moda priming and explicit memory in patients with verbal production deficits. Brain \& Cognition, 39, 133-146.

Dunn, J. C., \& KirSner, K. (EDS.) (2003). Forum on "What can we infer from double dissociations." Cortex, 39, 129-202.

Ellis, A. W., \& Young, A. W. (1996). Human cognitive neuropsychology: A textbook with readings (2nd ed.). Hove, U.K.: Psychology Press.

FARAH, M. J. (1994). Neuropsychological inference with an interactive brain: A critique of the "locality" assumption. Behavioral \& Brain Sciences, 17, 43-104.

Franks, J. J., Bilbrey, C. W., Lien, K. G., \& McNamara, T. P. (2000). Transfer-appropriate processing (TAP) and repetition priming. $\mathrm{Mem}$ ory \& Cognition, 28, 1140-1151.

Gardiner, J. M., Richardson-Klavehn, A., Ramponi, C., \& Brooks, B. M. (2001). Involuntary levels-of-processing effects in perceptua and conceptual priming. In M. Naveh-Benjamin, M. Moscovitch, \& H. L. Roediger III (Eds.), Perspectives on human memory and cognitive aging: Essays in honor of Fergus Craik (pp. 71-82). New York: Psychology Press.

Goldstein, L., \& Fowler, C. A. (2003). Articulatory phonology: A phonology for public language use. In N. O. Schiller \& A. Meyer (Eds.), Phonetics and phonology in language comprehension and production: Differences and similarities (pp. 159-207). Berlin: Mouton de Gruyter.

Graf, P., \& MANDler, G. (1984). Activation makes words more accessible, but not necessarily more retrievable. Journal of Verbal Learning \& Verbal Behavior, 23, 553-568.

Graf, P., Mandler, G., \& Haden, P. E. (1982). Simulating amnesic symptoms in normal subjects. Science, 218, 1243-1244.

Grodzinsky, Y., Piñango, M. M., Zurif, E., \& Drai, D. (1999). The critical role of group studies in neuropsychology: Comprehension regularities in Broca's aphasia. Brain \& Language, 67, 134-147.

HABIB, R., \& NyBERG, L. (1997). Incidental retrieval processes influence explicit test performance with data-limited cues. Psychonomic Bulletin \& Review, 4, 130-133.

Hawley, K. J., \& Johnston, W. A. (1991). Long-term perceptual memory for briefly exposed words as a function of awareness and attention. Journal of Experimental Psychology: Learning, Memory, \& Cognition, 17, 807-815.

HopkIns, R. H., \& EdwARds, R. E. (1972). Pronunciation effects in recognition memory. Journal of Verbal Learning \& Verbal Behavior, 11, 534-537.

JACKSON, A., \& MORTON, J. (1984). Facilitation of auditory word recognition. Memory \& Cognition, 12, 568-574.

JACOBY, L. L. (1983). Remembering the data: Analyzing interactive processes in reading. Journal of Verbal Learning \& Verbal Behavior, 22, 485-508.

Juola, P., \& Plunkett, K. (2000). Why double dissociations don't mean much. In G. Cohen, R. Johnston, \& K. Plunkett (Eds.), Explor ing cognition: Damaged brains and neural networks (pp. 319-327). New York: Psychology Press.

Kello, C. T. (2003). The emergence of a double dissociation in the modulation of a single control parameter in a nonlinear dynamical system. Cortex, 39, 132-134.

Kinder, A., \& Shanks, D. R. (2003). Neuropsychological dissociations between priming and recognition: A single-system connectionist account. Psychological Review, 110, 728-744.

KinoshitA, S. (2001). The role of involuntary aware memory in the implicit stem and fragment completion tasks: A selective review. Psychonomic Bulletin \& Review, 8, 58-69.

Loveman, E., van Hooff, J. C., \& Gale, A. (2002). A systematic investigation of same and cross modality priming using written and spoken responses. Memory, 10, 267-276.

Lukatela, G., Eaton, T., Sabadini, L., \& Turvey, M. T. (2004). Vowel duration affects visual word identification: Evidence that the mediating phonology is phonetically informed. Journal of Experimental Psychology: Human Perception \& Performance, 30, 151-162.

Lukatela, G., Frost, S., \& Turvey, M. T. (1999). Identity priming in English is compromised by phonological ambiguity. Journal of Experimental Psychology: Human Perception \& Performance, 25, 775-790.

Lukatela, G., \& Turvey, M. T. (1990). Automatic activation of pre- lexical phonology in visual word identification. European Journal of Cognitive Psychology, 2, 325-344.

Lukatela, G., \& Turvey, M. T. (1998). Reading in two alphabets. American Psychologist, 53, 1057-1072.

MacLeod, C. M., \& Masson, M. E. J. (1997). Priming patterns are different in masked word identification and word fragment completion. Journal of Memory \& Language, 36, 461-483.

McClelland, A. G. R., \& Pring, L. (1991). An investigation of crossmodality effects in implicit and explicit memory. Quarterly Journal of Experimental Psychology, 43A, 19-33.

McGeoch, J. A. (1932). Forgetting and the law of disuse. Psychological Review, 39, 352-370

McGeoch, J. A. (1942). The psychology of human learning: An introduction. New York: Longmans Green.

Miceli, G., Benvegnu, B., Capasso, R., \& Caramazza, A. (1997). The independence of phonological and orthographic forms: Evidence from aphasia. Cognitive Neuropsychology, 14, 35-69.

Mitchell, D. B., \& Bruss, P. J. (2003). Age differences in implicit memory: Conceptual, perceptual, or methodological? Psychology \& Aging, 18, 807-822.

Morris, C. D., Bransford, J. D., \& Franks, J. J. (1977). Levels of processing versus transfer appropriate processing. Journal of Verbal Learning \& Verbal Behavior, 16, 519-533.

MorTON, J. (1969). The interaction of information in word recognition. Psychological Review, 76, 165-178.

MorTON, J. (1979). Facilitation in word recognition: Experiments causing change in the logogen model. In P. A. Kohlers, M. E. Wrolstad, \& H. Bouma (Eds.), Processing of visible language (pp. 259-268). New York: Plenum.

Morton, J. (1980). The logogen model and orthographic structure. In U. Frith (Ed.), Cognitive processes in spelling (pp. 117-132). London: Academic Press.

Morton, J. (1982). Disintegrating the lexicon: An information processing approach. In J. Mehler, E. C. T. Walker, \& M. Garrett (Eds.), Perspectives on mental representation: Experimental and theoretical studies of cognitive processes and capacities (pp. 89-109). Hillsdale, NJ: Erlbaum.

Mulligan, N. W. (2003). Effects of cross-modal and intramodal division of attention on perceptual implicit memory. Journal of Experimental Psychology: Learning, Memory, \& Cognition, 29, 262-276.

NaIRne, J. S. (1990). A feature model of immediate memory. Memory \& Cognition, 18, 251-269.

NeAth, I., \& Surprenant,A. M.(2003). Humanmemory: An introduction to research, data, and theory. Belmont, CA: Thompson/Wadsworth.

Nilsson, L.-G., Wright, E., \& MURdock, B. B., JR. (1975). The effects of visual presentation method on single-trial free recall. Memory \& Cognition, 3, 427-433.

Patterson, K., \& Sewell, C. (1987). Speak and spell: Dissociations and word-class effects. In M. Coltheart, G. Sartori, \& R. Job (Eds.), The cognitive neuropsychology of language (pp. 273-294). London: Erlbaum.

Pilotti, M., Gallo, D. A., \& Roediger, H. L., III (2000). Effects of hearing words, imaging hearing words, and reading on auditory implicit and explicit memory tests. Memory \& Cognition, 28, 1406-1418.

Plaut, D. C. (1995). Double dissociation without modularity: Evidence from connectionist neuropsychology. Journal of Clinical \& Experimental Neuropsychology, 17, 291-321.

PORT, R. F. (1979). The influence of tempo on stop closure duration as a cue for voicing and place. Journal of Phonetics, 7, 45-56.

PORT, R. F. (1981). Linguistic timing factors in combination. Journal of the Acoustical Society of America, 69, 262-274.

Poulton, E. C. (1982). Influential companions: Effects of one strategy on another in the within-subjects designs of cognitive psychology. Psychological Bulletin, 91, 673-690.

Richardson-Klavehn, A., \& Gardiner, J. M. (1995). Retrieval volition and memorial awareness in stem completion: An empirical analysis. Psychological Research, 57, 166-178.

RichardSON-KLAVEHn, A., \& GaRdiner, J. M. (1996). Cross-modality priming in stem completion reflects conscious memory, but not voluntary memory. Psychonomic Bulletin \& Review, 3, 238-244.

Richardson-Klavehn, A., \& Gardiner, J. M. (1998). Depth-ofprocessing effects on priming in stem completion: Tests of the voluntarycontamination, conceptual-processing, and lexical-processing hypoth- 
eses. Journal of Experimental Psychology: Learning, Memory, \& Cognition, 24, 593-609.

Richardson-Klavehn, A., \& Gardiner, J. M. (1999). Conjoint dissociations reveal involuntary "perceptual priming" from generating at study. Consciousness \& Cognition, 8, 271-284.

Robertson, L. C., Knight, R. T., Rafal, R., \& Shimamura, A. P. (1993). Cognitive neuropsychology is more than single-case studies. Journal of Experimental Psychology: Learning, Memory, \& Cognition, 19, 710-717.

Roediger, H. L., III, \& Blaxton, T. A. (1987). Effects of varying modality, surface features, and retention interval on priming in wordfragment completion. Memory \& Cognition, 15, 379-388.

Roediger, H. L., III, \& Geraci, L. (2005). Implicit memory tasks in cognitive research. In A. Wenzel \& D. C. Rubin (Eds.), Cognitive methods and their application to clinical research (pp. 129-151). Washington, DC: American Psychological Association.

Roediger, H. L., III, \& McDermott, K. B. (1993). Implicit memory in normal human subjects. In H. Spinnler \& F. Boller (Eds.), Handbook of neuropsychology (Vol. 8, pp. 63-131). Amsterdam: Elsevier.

Roediger, H. L., III, Srinivas, K., \& Weldon, M. S. (1989). Dissociations between implicit measures of retention. In S. Lewandowsky, J. C. Dunn, \& K. Kirsner (Eds.), Implicit memory: Theoretical issues (pp. 67-84). Hillsdale, NJ: Erlbaum.

Roediger, H. L., III, Weldon, M. S., Stadler, M. L., \& Riegler, G. L. (1992). Direct comparison of two implicit memory tests: Word fragment and word stem completion. Journal of Experimental Psychology: Learning, Memory, \& Cognition, 18, 1251-1269.

RuECKL, J. G. (2002). The dynamics of visual word recognition. Ecological Psychology, 14, 5-19.

RueCKL, J. G., \& MATHEW, S. (1999). Implicit memory for phonological processes in visual stem completion. Memory \& Cognition, 27, 1-11.

Saltzman, E., \& Munhall, K. (1989). A dynamical approach to gestura patterning in speech production. Ecological Psychology, 1, 333-382.

Scarborough, D. L., Cortese, C., \& Scarborough, H. S. (1977) Frequency and repetition effects in lexical memory. Journal of Experimental Psychology: Human Perception \& Performance, 3, 1-17.
SlamecKa, N. J., \& Katsaiti, L. T. (1987). The generation effect as an artifact of selective displaced rehearsal. Journal of Memory \& Language, 26, 589-607.

Tulving, E. (2001). Does memory encoding exist? In M. Naveh-Benjamin, M. Moscovitch, \& H. L. Roediger III (Eds.), Perspectives on human memory and cognitive aging: Essays in honour of Fergus Craik (pp. 627). New York: Psychology Press.

Tulving, E., \& Schacter, D. L. (1990). Priming and human memory systems. Science, 247, 301-306.

Tulving, E., \& Thomson, D. M. (1973). Encoding specificity and retrieval processes in episodic memory. Psychological Review, 80, $352-373$.

Underwood, B. J. (1983). Attributes of memory. Glenview, IL: Scott, Foresman.

UTTAL, W. R. (2001). The new phrenology: The limits of localizing cognitive processes in the brain. Cambridge, MA: MIT Press.

VAN ORden, G. C., \& Goldinger, S. D. (1994). Interdependence of form and function in cognitive systems explains perception of printed words. Journal of Experimental Psychology: Human Perception \& Performance, 20, 1269-1291.

Van Orden, G. C., Jansen op de Haar, M. A., \& Bosman, A. M. T. (1997). Complex dynamic systems also predict dissociations, but they do not reduce to autonomous components. Cognitive Neuropsychology, 14, 131-165.

Van Orden, G. C., Pennington, B. F., \& Stone, G. O. (2001). What do double dissociations prove? Cognitive Science, 25, 111-172.

Van Wijnendaele, I., \& Brysbaert, M. (2002). Visual word recognition in bilinguals: Phonological priming from the second to the first language. Journal of Experimental Psychology: Human Perception \& Performance, 28, 616-627.

WELDON, M. S. (1991). Mechanisms underlying priming on perceptual tests. Journal of Experimental Psychology: Learning, Memory, \& Cognition, 17, 526-541.

WinNick, W. A., \& Daniel, S. A. (1970). Two kinds of response priming in tachistoscopic recognition. Journal of Experimental Psychology, 84, 74-81. 
APPENDIX A

Critical Words, Word Stems (Experiments 1-3), and Word Fragments (Experiment 4)

\begin{tabular}{|c|c|c|}
\hline Word & Word Stem & Word Fragment \\
\hline anteater & ant & _nt__t_r \\
\hline artist & art & _rt_s__ \\
\hline bullfight & bul_ & $-1 \mathrm{l}_{-} \_\mathrm{ht}$ \\
\hline captain & cap & ap__in \\
\hline corridor $^{\mathrm{a}}$ & cor & or__d_r \\
\hline herring & her & $\mathrm{h}$ r $n g$ \\
\hline crocodile & cro & _ro__d_1_ \\
\hline doorbell & door & _or_el_ \\
\hline escalator & $\mathrm{esc}$ & sc_l1 t \\
\hline festival & fes & _ _st_v_l \\
\hline foliage $^{\mathrm{a}}$ & fol_ & li_ge \\
\hline frostbite & fro & r_s_b_t_ \\
\hline garlic & gar & g__l_c \\
\hline hammock & ham & a_mo_- \\
\hline harness ${ }^{\mathrm{a}}$ & har & rn_rs \\
\hline marbleb $^{b}$ & mar & $\mathrm{ma}$ \\
\hline mermaid & mer & $\ldots$ rm__ d \\
\hline mockingbird & moc & _ck_n_b_r \\
\hline monster & mon & $\ldots \mathrm{ns}_{-} \mathrm{r}$ \\
\hline nutcracker & nut_ & _ut_r__ke_ \\
\hline parlora & par & rl_r \\
\hline peppermint ${ }^{\mathrm{a}}$ & pep & ep__rm__t \\
\hline pincushion & pin & _nc_sh_o_ \\
\hline porcelain & por & _or_el__n \\
\hline recreation & rec & ecc__at__n \\
\hline rollerblade & rol & ol__rb__d \\
\hline submarine & sub & _ub_ri_e \\
\hline turkey & tur & _rk_y \\
\hline unicorn & uni_ & n_co_n \\
\hline wigwam & wig & _g_am \\
\hline bedroom ${ }^{\mathrm{b}}$ & & _dr__m \\
\hline fingerprint $\mathrm{b}^{\mathrm{b}}$ & & in__r_r ${ }_{-\_} \mathrm{t}$ \\
\hline
\end{tabular}


APPENDIX B

Sequence of Word Stems (Top to Bottom, Left to Right) in Test List Presented to a Subgroup of Participants in Experiment 1

\begin{tabular}{|c|c|c|c|c|c|}
\hline Code & Word & Word Stem & Code & Word & Word Stem \\
\hline $\mathrm{F}$ & apple & app & $\mathrm{C}$ & wigwam & wig \\
\hline $\mathrm{F}$ & rabbit & $\mathrm{rab}$ & $\mathrm{F}$ & yellow & yel_ \\
\hline $\mathrm{F}$ & cactus & $\mathrm{cac}_{2}$ & $\mathrm{P}$ & bullfight & bul_ \\
\hline $\mathrm{F}$ & ginger & gin & $\mathrm{F}$ & video & vid \\
\hline $\mathrm{F}$ & foxhole & fox & $\mathrm{P}$ & festival & fes \\
\hline $\mathrm{F}$ & landlord & lan & $\mathrm{F}$ & ashtray & ash \\
\hline $\mathrm{F}$ & ribbon & $\mathrm{rib}$ & $\mathrm{C}$ & turkey & tur \\
\hline $\mathrm{F}$ & vessel & ves & $\mathrm{F}$ & jaguar & jag \\
\hline $\mathrm{F}$ & zebra & zeb_ & $\mathrm{C}$ & mockingbird & moc \\
\hline $\mathrm{F}$ & casket & cas & $\mathrm{F}$ & balcony & bal \\
\hline $\mathrm{P}$ & doorbell & door & $\mathrm{F}$ & nurse & nur \\
\hline $\mathrm{F}$ & tinsel & $\operatorname{tin}$ & $\mathrm{F}$ & dolphin & dol_ \\
\hline $\mathrm{C}$ & frostbite & fro & $\mathrm{C}$ & crocodile & $\mathrm{cro}_{-}$ \\
\hline $\mathrm{F}$ & television & tel_ & $\mathrm{F}$ & funnel & fun \\
\hline $\mathrm{P}$ & monster & mon & $\mathrm{C}$ & hammock & ham \\
\hline $\mathrm{F}$ & silver & sil_ & $\mathrm{F}$ & lumberjack & lum \\
\hline $\mathrm{C}$ & porcelain & por & $\mathrm{C}$ & captain & cap \\
\hline $\mathrm{F}$ & mandolin & man & $\mathrm{F}$ & locker & loc \\
\hline $\mathrm{P}$ & submarine & sub_ & $\mathrm{P}$ & unicorn & uni \\
\hline $\mathrm{F}$ & lullaby & lul & $\mathrm{F}$ & hospital & hos \\
\hline $\mathrm{C}$ & artist & art & $\mathrm{P}$ & anteater & ant \\
\hline $\mathrm{F}$ & border & bor & $\mathrm{F}$ & windshield & win \\
\hline $\mathrm{C}$ & escalator & esc & $\mathrm{C}$ & nutcracker & nut_ \\
\hline $\mathrm{F}$ & mirror & mir & $\mathrm{F}$ & magnet & mag \\
\hline $\mathrm{P}$ & garlic & gar & $\mathrm{P}$ & pincushion & pin \\
\hline $\mathrm{F}$ & pencil & pen & $\mathrm{F}$ & ticket & tic \\
\hline $\mathrm{P}$ & recreation & rec & $\mathrm{P}$ & herring & her \\
\hline $\mathrm{F}$ & underwear & und & $\mathrm{F}$ & torso & tor \\
\hline $\mathrm{C}$ & rollerblade & rol & $\mathrm{P}$ & mermaid & mer \\
\hline $\mathrm{F}$ & lemon & lem & $\mathrm{F}$ & trophy & tro \\
\hline
\end{tabular}


APPENDIX C

Test Sequence (Top to Bottom, Left to Right) in Experiment 5 Comprising 22 Warm-Up Items (W), 56 Fillers (F), 26 Primed Items (P), and 26 Unprimed Control Items (C)

\begin{tabular}{|c|c|c|c|c|c|c|c|c|c|}
\hline Code & Word & Code & Word & Code & Word & Code & Word & Code & Word \\
\hline $\mathrm{W}$ & newspaper & $\mathrm{F}$ & vacuum & $\mathrm{P}$ & rollerblade & $\mathrm{F}$ & cobblestone & $\mathrm{P}$ & escalator \\
\hline W & cigarette & $\mathrm{P}$ & cricket & $\mathrm{C}$ & hummingbird & $\mathrm{F}$ & mango & $\mathrm{C}$ & dolphin \\
\hline W & drumstick & $\mathrm{C}$ & captain & F & pumpkin & $\mathrm{P}$ & mockingbird & F & porcelain \\
\hline W & prisoner & $\mathrm{F}$ & limousine & $\mathrm{F}$ & wedlock & $\mathrm{C}$ & butterfly & $\mathrm{F}$ & ginger \\
\hline W & postcard & $\mathrm{F}$ & rocket & $\mathrm{P}$ & doghouse & $\mathrm{F}$ & projector & $\mathrm{P}$ & marble \\
\hline W & flagpole & $\mathrm{P}$ & foliage & $\mathrm{C}$ & wigwam & $\mathrm{F}$ & pencil & $\mathrm{C}$ & coffin \\
\hline W & barbecue & $\mathrm{C}$ & corridor & F & lullaby & $\mathrm{P}$ & pincushion & $\mathrm{F}$ & falcon \\
\hline W & jaguar & $\mathrm{F}$ & herring & $\mathrm{F}$ & popcorn & $\mathrm{C}$ & surfboard & $\mathrm{F}$ & runway \\
\hline W & hospital & $\mathrm{F}$ & platform & $\mathrm{P}$ & turkey & $\mathrm{F}$ & boomerang & $\mathrm{P}$ & bedroom \\
\hline W & clover & $\mathrm{P}$ & woodchuck & $\mathrm{C}$ & mermaid & $\mathrm{F}$ & zebra & $\mathrm{C}$ & fortress \\
\hline W & basket & $\mathrm{C}$ & tornado & $\mathrm{F}$ & sardine & $\mathrm{P}$ & submarine & $\mathrm{F}$ & bonfire \\
\hline W & lobster & $\mathrm{F}$ & mushroom & $\mathrm{F}$ & timpani & $\mathrm{C}$ & unicorn & $\mathrm{F}$ & spider \\
\hline W & kangaroo & $\mathrm{F}$ & blister & $\mathrm{P}$ & passport & $\mathrm{F}$ & helicopter & $\mathrm{P}$ & crocodile \\
\hline W & sunshine & $\mathrm{P}$ & recreation & $\mathrm{C}$ & peppermint & $\mathrm{F}$ & furnace & $\mathrm{C}$ & hammock \\
\hline W & cactus & $\mathrm{C}$ & festival & $\mathrm{F}$ & diplomat & $\mathrm{P}$ & panhandle & $\mathrm{F}$ & grasshopper \\
\hline W & pharmacy & $\mathrm{F}$ & ostrich & $\mathrm{F}$ & lemon & $\mathrm{C}$ & anteater & $\mathrm{F}$ & vessel \\
\hline W & jasmine & $\mathrm{F}$ & everglade & $\mathrm{P}$ & harbor & $\mathrm{F}$ & music & $\mathrm{P}$ & arcade \\
\hline W & fingerprint & $\mathrm{P}$ & soldier & $\mathrm{C}$ & balcony & $\mathrm{F}$ & microphone & $\mathrm{C}$ & magnet \\
\hline $\mathrm{W}$ & gasoline & $\mathrm{C}$ & scorpion & $\mathrm{F}$ & windmill & $\mathrm{P}$ & garlic & $\mathrm{F}$ & summit \\
\hline W & yellow & $\mathrm{F}$ & telescope & $\mathrm{F}$ & casket & $\mathrm{C}$ & frostbite & $\mathrm{F}$ & spaceship \\
\hline W & lettuce & $\mathrm{F}$ & stomach & $\mathrm{P}$ & doorbell & $\mathrm{F}$ & traveler & $\mathrm{P}$ & lumberjack \\
\hline W & embryo & $\mathrm{F}$ & handbag & $\mathrm{C}$ & silver & $\mathrm{F}$ & necklace & $\mathrm{C}$ & monster \\
\hline $\mathrm{F}$ & opera & $\mathrm{P}$ & bullfight & $\mathrm{F}$ & sandwich & $\mathrm{P}$ & nutcracker & $\mathrm{F}$ & farmland \\
\hline $\mathrm{P}$ & shampoo & $\mathrm{C}$ & trophy & $\mathrm{F}$ & skeleton & $\mathrm{C}$ & party & $\mathrm{F}$ & armchair \\
\hline $\mathrm{C}$ & artist & $\mathrm{F}$ & ladder & $\mathrm{P}$ & yoghurt & $\mathrm{F}$ & cartoon & $\mathrm{F}$ & bulldozer \\
\hline $\mathrm{F}$ & bandwagon & $\mathrm{F}$ & ashtray & $\mathrm{C}$ & starfish & $\mathrm{F}$ & octopus & $\mathrm{F}$ & refrigerator \\
\hline
\end{tabular}

\section{APPENDIX D \\ Questionnaire}

Congratulations! You have successfully completed the experiment that consisted of three different tasks:

TASK A: Pictorial representation of words,

TASK B: Listing the names of American presidents,

and

TASK C: Identification of words that were covered by auditory noise/bright dots.

PLEASE ANSWER THE FOLLOWING QUESTIONS AS BEST AS YOU CAN:

1. In your opinion, which task-A, B, or C-was the most interesting?

2. What do you think was the purpose of the experiment you just completed?

3. Did you notice any connection between the tasks A, B, and C?

4. What was your strategy in identifying the covered words in C?

$* * * * * * * * * * * * * * * *$

PLEASE TURN THE PAGE OVER

5. Did you notice that some of words in task A were also covered words in task C?

6. Did you try to use words from task A to help identify the covered words in task C?

Thank you!

(Manuscript received April 27, 2005;

revision accepted for publication March 16, 2006.) 